

\section{DISCLAIMER}

Ihis document was prepared as an account of work sponsored by an agency of the L nited States Government. Veither the Innited States Government nor the University of California nor any of their employees, makes any warranty, express or implied, or assumes any legal liability or responsibility for the accuracy, completeness, or usefulness of any information, apparatus, product, or process disclosed, or represents that its use would not infringe privately ouned rights. Reference herein to any specific commercial products, process, or service by trade name, trademark, manufacturer, or otherwise, does not necessarily constitute or imply its endorsement, recommendatıon, or favoring by the United States Government or the I'niversity of California. I he viens and opinions of authors expressed herein do not necessarils state or reflect those of the 1 nited States Government or the I niversity of California, and shall not be used for advertising or product endorsement purposes.

This document was produced and distributed under the auspices of the U.S. Department of Energy by Lawrence Livermore National Laboratory under Contract W-7405-Eng-48. 


\section{DISCLAIMER}

This report was prepared as an account of work sponsored by an agency of the United States Government. Neither the United States Government nor any agency Thereof, nor any of their employees, makes any warranty, express or implied, or assumes any legal liability or responsibility for the accuracy, completeness, or usefulness of any information, apparatus, product, or process disclosed, or represents that its use would not infringe privately owned rights. Reference herein to any specific commercial product, process, or service by trade name, trademark, manufacturer, or otherwise does not necessarily constitute or imply its endorsement, recommendation, or favoring by the United States Government or any agency thereof. The views and opinions of authors expressed herein do not necessarily state or reflect those of the United States Government or any agency thereof. 


\section{DISCLAIMER}

Portions of this document may be illegible in electronic image products. Images are produced from the best available original document. 
DOE/NCT-01

Distribution Category UC-46

DOE/NCT- 01

DE90 013082

\title{
Review of the State of Criticality of the Three Mile Island Unit 2 Core and Reactor Vessel
}

\author{
William R. Stratton \\ TMI-2 Safety Advisory Board \\ GPU-Nuclear \\ Middletown, PA 17057
}

April 15, 1987

[Manuscript date: July, 1985]

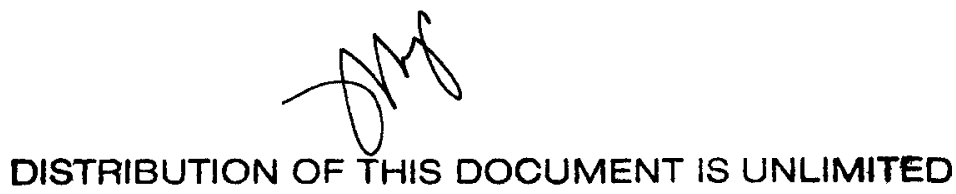

Avalable from Nuclear Critac lity Information System - L 390 - Lahicnce Lacrmore

National Laboratory - 7000) East Avenue - Livermote, CA 94550 


\section{Contents}

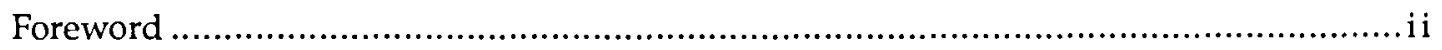

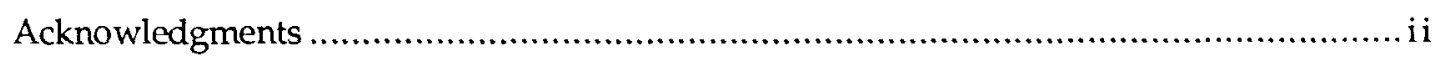

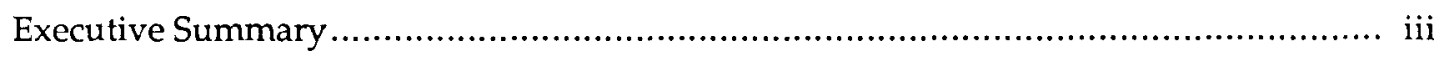

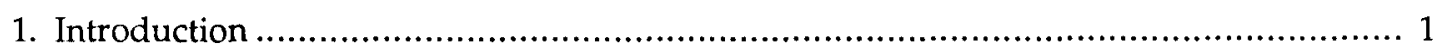

2. Description of the TMI-2 Core, Reactor Vessel, and Primary Coolant System ........................................................................ 2

3. Methods of Estimating Neutron Multiplication ................................................

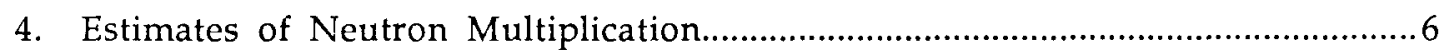

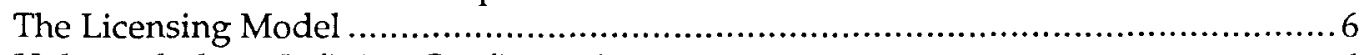

Unbounded or Infinite Configurations................................................................

The Oak Ridge Model .......................................................................... 6

The Los Alamos Model .....................................................................

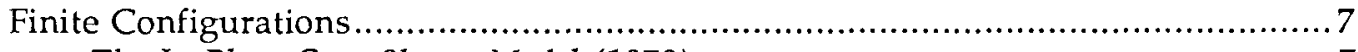

The In-Place Core Slump Model (1979) ….............................................. 7

The Rubble Model (1984) ................................................................... 7

Summary of Model Results ...................................................................

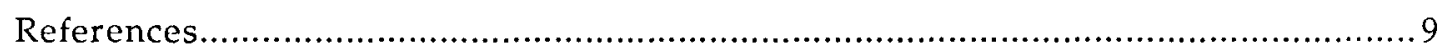

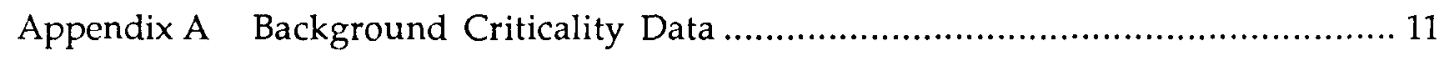

Appendix B Analytical Models and Computational Results ............................... 16

Appendix C Computer Code Benchmarking............................................................ 29

Appendix D The Meaning of Criticality and Margins of Safety ........................... 30

Appendix E Borated Water Monitoring and Supply ......................................... 32

Appendix F Regulatory Shutdown Requirements ......................................... 35 


\section{Foreword}

In response to a request from General Public Utilities Nuclear Corporation, I have completed the following review of the state of criticality in the Three Mile Island Unit 2 (TMI-2) reactor.

The preparation of this report involved reviewing a number of studies that examined the neutron multiplication of the TMI-2 core. The earliest of these studies was completed in the summer of 1979, while the most recent studies date from 1984. Some of the reactor models are quite conservative, even unrealistic, while others are much more reasonable but still conservative because of the unknown factors discussed in this report.

An enormous amount of work has been done on this subject, reflecting both its importance and its intrinsic interest as a technical problem. Five separate studies have been selected to show the range of models and to illustrate the reactivity margin from critical.

Briefly, the reactor is very subcritical and, with the high boron concentration being maintained, there is no possibility of an accidental criticality. The most realistic estimate of the neutron multiplication quoted here is 0.86 . However, because of several conservatisms incorporated in the model, I judge the neutron multiplication to have been substantially less than than this by at least $5-10 \%$. The operational conclusion of the report is that, with the high boron concentration maintained, defueling can proceed with confidence that the reactor will remain subcritical.

I have not assumed that all potential readers of this report will be familiar with such areas as the meaning of criticality or criticality physics, computer programs for evaluating the neutron multiplication, the state of the fuel, or margins of safety. Background in these areas is provided in some of the chapters and appendices. Occasionally, there are redundancies on some technical matters, again to assist the reader.

\section{Acknowledgments}

A number of individuals and organizations have assisted in the preparation of this report, for which I am most grateful. Dr. Raymond Murray and Mr. Robert Brodsky prepared early drafts of some of the chapters and appendices, and reviewed the entire document prior to the final draft. The Safety Advisory Board supported the effort throughout, and the document was reviewed by Dr. Norman Rasmussen, Mr. Lombard Squires, and Mr. Ronald Fillnow, the Executive Secretary. I am especially pleased to acknowledge the very useful technical review and comments by Ms. Patricia Smith, Mr. Philip Bradbury, Mr. G. Richard Skillmen; and editorial advice by Ms. Shelly Owrutsky. Finally, I thank the GPU-Nuclear staff, in particular the word-processing group, without whose efforts the project would have been much more difficult. 


\section{Executive Summary}

The events during the early hours of the Three Mile Island Unit 2 (TMI-2) accident on March 28, 1979 caused the fuel in the reactor core to crumble or disintegrate, and then subside into a rubble structure more compact than its normal configuration. The present height of the core is about seven feet, five feet less than its normal configuration of 12 feet. $^{1}$

With the same boron content and some or all of the control rod and burnable poison rod material as the normal core configuration, the collapsed structure is calculated to be more reactive. However, the reactor is assuredly subcritical at present because of the extraordinarily high boron concentration maintained in the coolant water.

Many studies of the neutron multiplication of the TMI-2 reactor have been completed since 1979.2-5 These efforts culminated in the "Criticality Report for the Reactor Coolant System at TMI-2" (October 1984). ${ }^{6}$ In that report, a conservative model was chosen, which assumed the fuel to be in the lower head with the most highly enriched fuel (approximately $3 \%$ $235 \mathrm{U}$ ) surrounded by a mixture of the remaining fuel. The bottom surface was reflected by the steel vessel, while the upper surface was somewhat rounded. Optimum moderation was chosen, and all fuel cladding and solid control materials were removed. This "incredible" model was found to be subcritical even with allowances for calculational uncertainties estimated by computer code benchmarking studies.

After the development of this model, the first video examination of the lower plenum showed that as much as $1000-2000 \mathrm{~kg}$ of core material may have become liquefied. The model has been modified conservatively to allow for this effect, with the result that the neutron multiplication factor $\left(k_{\text {eff }}\right)$ is estimated to be slightly less than the earlier model (in other words, $k_{\text {eff }}<0.99$ ).

Four additional and different physical models are discussed briefly in the report to illustrate the margin of subcriticality, to provide a better estimate of the neutron multiplication factor, and to provide some understanding of the criticality effects of the important parameters. The first two are infinite arrays of fuel pins (to represent a compacted configuration) and infinite arrays of $\mathrm{UO}_{2}$ spheres (to represent rubble). ${ }^{7,8}$ The two methods, with their different and conservative geometries, agree well. As a result, it can be deduced that the multiplication factor is about 0.91 for an infinite array of average enrichment fuel $(2.57 \%)$. The multiplication factor of the finite system will be less than this value.

Two different finite, cylindrical models of a collapsed core are also presented in this report. Both are believed to be conservative, but these models are much more realistic than the licensing or the infinite models, and are calculated to have multiplication factors between $0.86-0.90$ for a boron concentration of $4350 \mathrm{ppm}$. The actual multiplication factor of the TMI-2 core is expected to be lower than this estimate by 5 or $10 \%$. Also, because the concept of criticality or neutron multiplication is not obvious or well known, some additional background information is provided, along with related ideas leading to a measure of the margin of safety.

To assure that an adequate liquid level and boron concentration are maintained in the reactor vessel, certain measurements must be made periodically, and equipment must be in place prior to defueling activities. The approach of the TMI-2 recovery program to these matters has been found to be adequate and is discussed briefly here. 
The conclusion of this review is that the reactor is now very far subcritical with a boron concentration of $4350 \mathrm{ppm}$ or more, and no conceivable rearrangement of fuel can create a critical state. Careful administrative control to maintain the boron concentration of the reactor coolant close to $5000 \mathrm{ppm}$, and controls to rigorously exclude addition of unborated water to the primary system, provide additional assurance that subcriticality will be maintained. The immediate corollary is that the defueling of the reactor vessel can proceed as planned, with complete confidence that such operations will remain subcritical. 


\section{Review of the State of Criticality of the Three Mile Island Unit 2 Core and Reactor Vessel}

\section{Introduction}

The purpose of this report is to review the available information about the physical and chemical state of the fuel in the Three Mile Island Unit 2 (TMI-2) reactor, to review calculations of the reactivity of the core in its present configuration, and to estimate the margin of safety and show what level of dissolved boron is needed to maintain subcriticality during defueling. Some background information on the meaning of reactivity and the criticality physics of slightly enriched uranium has been added as an Appendix.

Shortly after the accident, reactivity calculations were deemed to be necessary because the core configuration had changed, though it was not known accurately. These studies were undertaken by Babcock and Wilcox, General Public Utilities, the Oak Ridge National Laboratory, and the Nuclear Regulatory Commission (NRC). ${ }^{2-5}$ The major motivation was to determine the required boron content for a safe subcritical state, but the uniqueness of the TMI-2 situation added special interest for such studies. Many comprehensive calculations and studies have been completed since 1979, and summaries of some of these are included in section 4 and Appendix B of this report.

These studies culminated in the October 1984 "Criticality Report for the Reactor Coolant System at TMI-2", 6 authored by members of the staff at Three Mile Island. The "Criticality Report" describes a conservative model and establishes a conservative estimate of code accuracy. With the boron concentration conservatively held at $4350 \mathrm{ppm}$, the neutron multiplication factor $\left(k_{\mathrm{eff}}\right)$ was calculated to be less than 0.99 . This model and study has been reviewed favorably by the NRC.

After the first video examination of the lower plenum, investigators realized that the core was not entirely rubble, but that a fraction of the core could have fused into small masses and created a different configuration, which would be either more or less reactive. This effect has been considered in the model with the result that the neutron multiplication is about the same as estimated by the the earlier model.

The conservative model above, referred to as the "licensing model," establishes an upper bound to the neutron multiplication factor but gives little information as to the actual numerical value. More realistic estimates are obtained in section 4 and Appendix $B$ of this report by two "infinite" models and two "finite" models. These four evaluations, all different and all conservative, show that $k_{\infty}<0.91$ from the infinite models and $k_{\text {eff }}=0.86$ from the finite models (average fuel enrichment $=2.57 \%$ $\left.{ }^{235} \mathrm{U}\right)$. Small corrections to these calculational results are presented in the discussion. 


\section{Description of the TMI-2 Core, Reactor Vessel, and Primary Coolant System}

During the first few hours of the accident on March 28 1979, the core of the TMI-2 reactor was denied adequate cooling water and slowly overheated. After about three hours, water was injected into the reactor vessel, causing the fuel assemblies to shatter and crumble to a configuration quite different from their normal state. (Further details on the accident are available in Ref. 1.) Since that time, video and sonar investigations have revealed a great deal of information about the state of the fuel, cladding, and steel support structure. Briefly, it is known that the fuel pins in at least the top part of the core have disintegrated and slumped downward. The upper surface of this rubble is now about five feet below the upper plenum structure. The height of the remaining core is approximately seven feet, instead of the normal twelve feet. ${ }^{9}$

The rubble appears to consist of disintegrated fuel pins, fuel pellets, fractions of fuel pellets, shards of cladding, and some $\mathrm{B}_{4} \mathrm{C}$ pellets (from burnable poison rods). Closer examination of samples removed from the vessel have verified this general description. ${ }^{10}$

Probes have been inserted into the rubble to investigate its characteristics. These probes have revealed that an apparently solid mass exists about three feet below the surface of the rubble. ${ }^{11}$ This structure apparently exists across the full diameter of the core, and the characteristics of such a structure probably will not be completely determined until defueling is started. Its existence, however, can cause a change in the evaluation of the core reactivity because of the criticality characteristics of uranium enriched to only a small percentage of ${ }^{235} \mathrm{U}$ (see Appendix A). The mass could be fuel pins and core structure that have merely fused together with steel, or it might represent a mass that had been, or had nearly been, molten.

More recently, a video inspection of the bottom of the reactor vessel was performed to determine if fuel or rubble had reached this region. ${ }^{12}$ This examination showed a mass of material estimated to be $1000-2000 \mathrm{~kg}$ in the bottom of the vessel (possibly $7-15 \%$ of the core), material that appears to have been molten or at least liquefied. The appearance of the material in the lower plenum is that of a liquid that was chilled and cracked into centimeter-sized pieces. This observation also suggests that fuel pellets in at least some parts of the core region may have fused together to create an array of pieces of a few centimeters diameter. The observation also suggests that a void may have been created in the lower part of the core. The existence of such an array could either increase or decrease the multiplication factor, $\left(k_{\text {eff }}\right)$ while a void in the core would certainly decrease the $k_{\text {eff }}$. The possible increase in reactivity, discussed in Section 4 and Appendix $B$, could be as much as 2 or $3 \%$. This effect is derived from the knowledge that an array of fuel pins or a cluster of fused fuel pellets of a few centimeters diameter is more reactive than a rubble bed or a homogeneous mixture of fuel and water. The magnitude of the change depends on the moderation, the particle size, and the poison content. If the fused pellets are more than a few centimeters across, the effect is to decrease the $k_{\text {eff }}$. If this should be the case, a significant part of the core would contribute little to the neutron multiplication.

In the criticality evaluations discussed below, all the fuel is assumed to be in the lower plenum in the licensing model, but above the core support plate in the two finite rubble models. Both assumptions are conservative because fissile uranium must be concentrated in a single volume to achieve a high multiplication.

The boron concentration currently is maintained between 4950 ppm and about 5200 ppm, higher than the license value of 4350 ppm. This concentration was decided upon in early 1984, prior to removing the reactor head, and was chosen to assure a subcritical state, no matter what defueling operations were 
conducted. Before the accident on March 28, 1979, the boron concentration was about 1050 ppm, ${ }^{13}$ but the borated water storage tank-the water source for the high-pressure injection system-had been maintained at $2300 \mathrm{ppm}$. Presumably, then, water at this concentration was used to refill the vessel about 3-1/2 hours following the start of the accident, and this boron concentration (or less) was present when the core collapsed. This description is supported by analyses of a sample of the primary coolant taken on March 29, 1979 (after the main pumps were in operation again). The sample was analyzed by two laboratories with two differing determinatigns of boron content $-1750 \mathrm{ppm}$ and

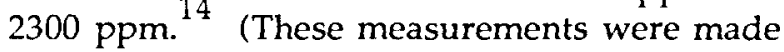
with very small samples, however, and the boron concentration values should be considered only as guides. Similarly, there is no absolute assurance that the borated water storage tank was the only source of water for the high-ressure injection system.) Within a few days, the boron concentration was increased to about $3000 \mathrm{ppm}$, later increased to about $3500 \mathrm{ppm}$, and was maintained at this value until it was raised again in 1984. Since the time of the accident, there have been no indications of re-criticality, even at boron concentrations that may have been as low as $2300 \mathrm{ppm}$.
The fuel had a burnup of approximately 94 MWD MTU* before the accident. This power history is sufficient to have generated significant fission-product neutron poisons. A conservative estimate of this negative reactivity is about $1.8 \%$ (i.e., the neutron multiplication factor calculated without this effect should be reduced by 0.018$){ }^{6}$

A careful search has been underway to find any accumulations of fuel external to the reactor vessel. To date, no major amounts have been found; however, these activities are still in progress. In the evaluations listed in later sections of this report, all fuel is assumed to be within the pressure vessel, which is again a conservative assumption for evaluating the reactivity of the core.

In Section 4 and Appendix B, the models for calculation of the neutron multiplication factor use the information about the core that was available at the time of the calculation. Where unknown factors existed, a conservative choice was made. However, the objective is to procced from the most conservative and unrealistic models to more reasonable models so as to provide acceptable, but still conservative, estimates of the reactivity of the reactor vessel as it now exists.

MWD/MTU-Megawatt days per metric tonne $(1000 \mathrm{~kg}$ ) of uranium; the customary unit for burnup of reactor fuel. 


\section{Methods of Estimating Neutron Multiplication}

The design and operation of nuclear reactors, and the description of fissile systems, has been based over the years on calculations using the mathematical theory of neutron transport and multiplication, supplemented by a large number of experimental measurements. Calculations have various levels of sophistication, depending on their purpose (i.e., tutorial, conceptual design, detailed final design, reactor operations, fuel management, and storage). Computer codes for calculating the behavior of neutron multiplying systems have evolved along different lines at various national laboratories and reactor manufacturing organizations. Although each code seeks to describe the same basic phenomena and to yield values of neutron fluxes and multiplication factors, the methodologies used are quite different.

One distinction is the level of detail in the neutron cross sections. Measurements of neutron interaction with materials have provided increasing detail and accuracy, with the old BNL-325 ("Barn Book") being supplanted by the Evaluated Nuclear Data Files, e.g., ENDF-B/V. The way the cross sections are processed and used depends on the detail of neutron energy spectra that is required for adequate accuracy. In the design of the earliest reactors, for example, a single thermal neutron cross-section set was adequate, while a two-energy group model was applied to the design of early research and power reactors. Existing commercial codes such as PDQ use five energy groups; the Hansen-Roach 16-group set is also widely used; for sophisticated benchmarking codes such as SAM-CE, thousands of point values of cross sections give essentially continuous crosssection treatment. The Monte Carlo Neutron Photon Code (MCNP) uses the ENDF-B/V data file in an essentially direct manner. ${ }^{15}$

Neutron motion analyses have evolved differently as well. All methods start with the basic processes of neutron capture, scattering, and fission. The neutron transport equation is written as a statement of process balance in terms of direction of particle motion and energy. An approximate solution can be obtained by the use of discrete ordinates, involving the representation of the neutron flux as a function of specific spatial locations, energy groups, and directions of motion. A widely used example is the $S_{n}$ method with the ANISN code.

Alternatively, the average properties of a cell-consisting of fuel, moderator, and structure-are determined by a transport model such as THERMOS or LEOPARD, and the results are used in the neutron diffusion approximation, such as is embodied in PDQ-7. This is a finitedifference solution of the diffusion equations that is applied to the design and operation of the reactor core with different fuel regions and control rod locations. The method is quite accurate (a fraction of a percent in $k_{\text {eff }}$ ) for geometries and materials similar to those of standard power-reactor designs, for which the method was developed. However, its results become less certain when applied to new and complex three-dimensional arrangements, because the number of mesh points is limited.

A third, completely different approach is statistical in nature. The Monte Carlo method starts with the basic motions and interactions between particles, but tracks individual neutron histories from origin to loss by capture or leakage. A widely used program is KENO, versions IV or Va. Cross-sections are first processed by programs such as BONAMI or NITAWL, and supplied to XSDRNPM, which develops average cell properties from which the value of $k_{\infty}$ can be calculated. These data are supplied to KENO, which can treat complicated geometries such as chemical process vessels or arrays of fuel containers. Because of its statistical nature, the accuracy of the method is dependent on the number of histories used. In addition to the statistical uncertainty, the program may have a certain bias related to the degree of neutron moderation. The 
net result yields a code uncertainty on the order of $1-2 \%$ in the calculated $k_{\text {eff }}$.

These Monte Carlo codes must be used with care, since they may not recognize the existence of small regions of high neutron multiplication. The methods are widely used for nuclear criticality prevention in systems that must be designed and operated with the possibility of accidental criticality. They use techniques that need not be exceedingly accurate, but must be assured to be conservative.
A good description of the application of Monte Carlo appears in Ref. 16; the Monte Carlo code MCNP was used for the calculations in Ref. 7 .

The evaluations of the neutron multiplication (with the associated calculations) given in Section 4 and the Appendices use all the techniques mentioned abover, but discuss especially the $S_{n}$ method and the Monte Carlo technique. Each has its advantage for certain configurations. 


\section{Estimates of Neutron Multiplication}

To illustrate the magnitude of the TMI-2 criticality studies and the degree of conservatism involved, five studies with modifications are described briefly in this section, along with a summary of the results. The discussion proceeds from the most conservative study, the licensing model, to less unrealistic assumptions and models. Because of the complexity involved, most of this material is discussed in greater detail in Appendix $B$.

\section{The Licensing Model ${ }^{6}$}

This model was developed following a policy decision in 1984 that the boron poison should be increased to a concentration that would protect against all conceivable conditions; this model and the associated calculations have been reviewed and approved by the NRC. The boron concentration was chosen with the aid of a degraded core model that was deemed to be conservative enough to cover all situations; it was chosen before a video examination of the lower plenum of the reactor vessel was completed.

The following assumptions describe the model:

1. All the fuel, without cladding, structural material, or poison, is in the lower plenum with the $3 \%$ enriched fuel at the center surrounded by a mix of the remaining fuel.

2. The neutron reflector from below is the steel of the reactor vessel.

3. The top surface is lenticular and reflected by borated water.

4. The moderator-to-fuel ratio was optimized for maximum neutron multiplication.

5. Burnup credit is taken only for the most highly enriched fuel. imposed.

6. A computer program bias of 0.025 was

7. The boron concentration is 4350 parts per million (ppm).

Given these conditions, the $k_{\text {eff }}$ was calculated to be $<0.99$, a value regarded as an upper limit for the neutron multiplication of the core.

Subsequent to this study, the first video examination of the lower plenum showed that $1000-2000 \mathrm{~kg}$ of core material could have flowed to this area and solidified. This observation required a modification to the model described above because an array of small volumes can be more critical than a homogeneous mixture or a rubble bed. The optimum size is a very few centimeters, if moderated adequately. Larger pieces will be subcritical, considering the amount of material present.

To modify this model, the assumptions were made that $30 \%$ of the core had liquefied (enrichment $2.57 \%$ ) and formed into pieces of optimum size and with optimum moderation. This assembly was placed at the center of the model described above, surrounded by $70 \%$ of the $3 \%$-enriched fuel and, outside of this, the remaining fuel, all with optimum moderation. The neutron multiplication factor of this model was found to be about the same as that of the first model, $k_{\text {eff }}<0.99$.

\section{Unbounded or Infinite Configurations}

A useful concept in the evaluation of criticality safety problems is the multiplication factor of the infinite system, denoted as $k_{\infty}$, which assumes that the model cell is replicated indefinitely in all directions. It is obvious that the multiplication factor of the finite system ( $k_{\text {eff }}$ ) will be less than the $k_{\infty}$ value because neutron leakage (and loss) has been ignored. Parametric studies of this type have been completed at the Oak Ridge National Laboratory (ORNL) and the Los Alamos National Laboratory (LANL).

\section{The Oak Ridge Model ${ }^{8}$}

The Oak Ridge model consisted of infinite arrays of fuel pins of 2.0, 2.57, and $3 \%$ en 
richment with different lattice spacings and a range of boron concentrations, both with and without cladding. These data can be examined for an estimate of an upper bound of the multiplication factor of the TMI-2 core at a boron concentration of $4350 \mathrm{ppm}$. Two estimates for the $k_{\infty}$ of this model are 0.96 .3\% enrichment) and 0.91 ( $2.57 \%$ enrichment). Details can be found in Appendix B.

\section{The Los Alamos Model 7}

The second infinite model is an array of spheres of $\mathrm{UO}_{2}$, enriched to $3 \%{ }^{235} \mathrm{U}$, with a constant water volume fraction of 0.48 . Several boron concentrations were considered, and the model had no cladding material, or structural or fixed poisons included.

This study, independent of the Oak Ridge model and performed with different computer programs and cross-section sets, showed very reasonable agreement for the special case of $3 \%$-enriched fuel, no cladding, and the boron concentrations currently used. More detail can be found in Appendix B.

Clearly, these estimates of the neutron multiplication factor are conservative-larger than can be expected in the actual case. The TMI-2 core structure is not a regular, infinite array of pins or spheres; it is finite and in a state of rubble. Some structural material is in the rubble, as is some poison material. Although the core has been subcritical at substantially lower boron concentrations, this is not applied explicitly to these analyses.

Nevertheless, the fact that these conservative evaluations are substantially subcritical is reassuring.

\section{Finite Configurations}

A better estimate of the multiplication factor can be obtained from models that are more realistic regarding the size, location, and configuration of fuel in the reactor vessel. Two models that are of interest and provide better estimates of reactivity have been created by the ORNL group.

\section{The In-Place Core Slump Model (1979) ${ }^{2}$}

This model was created before any details were known about the fuel slumping and becoming rubble. It was assumed that the fuel pins and cladding expanded radially and slumped axially while maintaining constant volume. A parametric study of $k_{\text {eff }}$ versus core height was thus obtained. Given more recent knowledge about the amount of slumping, the model can be used to estimate the neutron multiplication factor with cladding but without considering structural material or control rods or fixed burnable poison. The estimate for this model with $4350 \mathrm{ppm}$ boron is $k_{\text {eff }}=0.91$. Details of this study can be found in Appendix B.

\section{The Rubble Model (1984) ${ }^{8}$}

This model was created subsequent to the video observation that the fuel appeared to have become a rubble pile of fuel pellets, fragments, shards of cladding, and burnable poison pellets. The height of the core was about seven feet compared with its normal height of 12 feet. The study considered a number of rubble structures and part-length fuel pins, but the most conservative model consisted of seven feet of rubble with no cladding, no structures, or poison. The neutron multiplication for this case, with an average enrichment of $2.57 \%$ and $4350 \mathrm{ppm}$ boron in the coolant, is 0.91 . The data presented in Appendix $\mathrm{B}$ allow for the estimate to be modified to include the cladding (core volume remaining constant); this modified estimate of the multiplication factor is 0.86 . Small changes caused by fuel burnup, fuel clumping, poison, and possible code bias are also presented.

\section{Summary of Model Results}

In conclusion, by making use of calculations completed in 1979 and additional studies completed in 1984, the TMI-2 core has been shown to be subcritical by a substantial margin with the present boron concentration.

1. The licensing model (October 1984, criticality study) shows that the reactor is subcritical even with a number of extraordinarily 
conservative assumptions. The $k_{\text {eff }}<0.99$ for any configuration if the boron concentration is $4350 \mathrm{ppm}$ or more. Modifications to allow for fuel melting have been incorporated.

2. Recent work includes very extensive $k_{\infty}$ calculations of fuel pins at various lattice spacings (pitch), fuel enrichments, and boron content. The $k_{\infty}$ for fuel pins of average enrichment $(2.57 \%)$ with cladding intact is only 0.96 for 4350 ppm boron; an estimate using a better value of water content is $k_{\infty}=0.91$. The conservative bias for these $k_{\infty}$ results was judged to be several percent.

3. The $k_{\infty}$ calculations for 2 - and 3\%-enriched spheres of various sizes, moderation, and boron poisoning have been completed to compare with the pin studies. Different Monte Carlo codes and cross-section sets were used. The two studies agree reasonably well for the boron concentration of interest.

4. The 1979 study of the collapsing pin structure can be applied to the present condition. From this study, the $k_{\text {eff }}$ was calculated to be 0.93 for a boron concentration of $3180 \mathrm{ppm}$, and was estimated to be less than 0.91 for $4350 \mathrm{ppm}$.

5. A model was developed that provides for a parametric study of the core with progressively greater amounts of fuel converted to rubble. This model (with conservative assumptions) shows that the $k_{\mathrm{eff}}$ of the finite system increases monotonically with increasing amounts of the core changed to rubble. For those cases fully converted to rubble and with 4350 ppmboron:

- For the average enrichment throughout without cladding, $k_{\text {eff }}=0.91$.

- For the artificial case of requiring all fuel to be $3 \%$ enriched without cladding, $k_{\text {eff }}=0.95$.

- For fuel of average enrichment with cladding, $k_{\text {eff }}=0.86$.

Other conservatisms in this rubble model include no structural material, burnable poison, or control rod material. The density of the rubble was chosen for the most reactive case.

These criticality evaluations of several models of the TMI-2 core show that, even with very conservative assumptions, the core is subcritical by $10-15 \%$. The exact value is not known and cannot be determined exactly because of the unknown details of the fuel particle size, distribution, cladding, structural material, and poison. However, the overwhelming conclusion is that, so long as the boron content is held at $4350 \mathrm{ppm}$, the fucl will remain subcritical with a substantial reactivity margin, and complete freedom may be allowed in the process of removing fuel. 


\section{References}

1. Nuclear Safety Analysis Center (corporate author), Analysis of Three Mile Island-Unit 2 Accident, Revised. 1980; Electric Power Research Institute, Palo Alto, CA, NSAC-1 (1980).

2. R.M. Westfall, J.T. West, G.E. Whitesides, and J.T. Thomas, Criticality Analysis of Disrupted Core Models of Three Mile Island-Unit 2, Oak Ridge National Laboratory, Oak Ridge, TN, ORNL/CSD/TM-106 (1979).

3. E.W.Barr, J.P. Colletti, J.A. Esly, and J.D. Luoma, TMI-2 Post Accident Criticality Analysis, Babcock and Wilcox Company, Lynchburg, VA, TDR-049 (1979).

4. C.R. Marotta, Recriticality Potential of the TMI-2 Core, Nuclear Regulatory Commission, Office of Nuclear Material and Safeguards, Washington, DC (1979); also in Transactions of the American Nuclear Society, (American Nuclear Society, La Grange Park, IL, 1980), 35, pp. 272-274.

5. Babcock and Wilcox (corporate author), TMI-2 Criticality Evaluation Notebook, Babcock and Wilcox Company, Lynchburg, VA, NPGD-TM534 (1979); transmitted by letter from G.E. Kulynych, Babcock and Wilcox Company, to R.F. Wilson, GPU Service Co., Parsippany, NJ (December 11, 1979).

6. GPU-Nuclear (corporate author), Criticality Report for the Reactor Coolant System, GPU-Nuclear, Middletown, PA (Bechtel document number 15737-2-N09001) (1984).

7. T. McLaughlin, Criticality Safety Group, Los Alamos National Laboratory, Los Alamos, NM, private communication (1985).

8. J.T. Thomas, Effect of Boron and Gadolinium Concentrations on the Calculated Neutron Multiplication Factor of $\mathrm{U}_{3} \mathrm{O}_{2}$ Fuel Pins in Optimum Geometry, Oak Ridge National Laboratory, Oak Ridge, TN, ORNL/CSD/TM-218 (1984).

9. GPU-Nuclear (corporate author), Three Mile Island-Unit 2 Report on the Insertion of a Camera into the TMI-2 Reactor Vessel Through a Leadscrew Opening, GPUNuclear, Middletown, PA (1982).

10. GPU-Nuclear (corporate author), Draft Preliminary Report: TMI-2 Core Debris Grab Samples-Analysis of First Group of Samples, GPU-Nuclear, Middletown, PA, EG\&G-TMI-6630 (1984).

11. GPU-Nuclear (corporate author), Core Debris Bed Probing, GPU-Nuclear, Middletown, PA, TPB-84-008, Rev. 1 (1985).

12. GPU-Nuclear (corporate author), Reactor Lower Head Vidco Inspection, GPUNuclear, Middletown, PA, TPB-85-006, Rev. 1 (1985). 
13. GPU-Nuclear (corporate author), TMI-2 Chemistry Logbook, GPU-Nuclear, Middletown, PA (1979).

14. GPU-Nuclear (corporate author), Reactor Coolant System Sample Results, GPUNuclear, Middletown, PA, data report TPO/TMI-122, Rev. 1 (1985).

15. Los Alamos Monte Carlo Group, $M C N P-A$ General Monte Carlo Code for Neutron and Photon Transport, Version 2B, revised ed., Los Alamos National Laboratory, Los Alamos, NM, LA-7396-M (1985).

16. D. Dickinson and G.E. Whitesides, "The Monte Carlo Method for Array Criticality Calculations, Nuclear Technology, 30, p. 166 (1976).

17. H.C. Paxton, Critical Data for Nuclear Safety Guidance, Los Alamos National Laboratory, Los Alamos, NM, LANL-2415 (1960).

18. T.H. Brown, Calculated Criticality Data for Low Enriched $\mathrm{UO}_{2}$-Water Mixture, Los Alamos National Laboratory, Los Alamos, NM, H-6-170 (1982).

19. GPU-Nuclear (corporate author), Hazards Analysis: Potential for Boron Dilution of the Reactor Coolant System, GPU-Nuclear, Middletown, PA, 4430-84-007R, Rev. 1 (1984).

20. GPU-Nuclear (corporate author), Division System Description for Reactor Building Sump Recirculation System (SRS), GPU-Nuclear, Middletown, PA, SD 3510-012 (1984).

\section{Additional References}

American Nuclear Society, Nuclear Criticality Safety Division, "Criticality Safety and TMI," in Transactions of the American Nuclear Society, (American Nuclear Socicty, La Grange Park, IL, 1980), 35, pp. 270-277.

J.R. Worsham, F.A. Alcorn, L.A. Hassler, G.M. Jacks, F.G. Welfare, and J.J. Woods, Methods and Procedures of Analysis for TMI-2 Criticality Calculations to Support Recovery Activities Through Head Removal, Babcock and Wilcox Company, Lynchburg, VA, BAW-1738 (1982). 


\section{Appendix A \\ Background Criticality Data}

Uranium enriched to less than about $6 \%{ }^{235} \mathrm{U}$ has a safety or criticality characteristic completely different from highly enriched $\left(93 \%{ }^{235} \mathrm{U}\right)$ uranium. The uranium used in power reactors $(2-3 \% 235 \mathrm{U})$ cannot become a critical, reacting system unless it is mixed with a moderator (such as water, $\mathrm{D}_{2} \mathrm{O}$, beryllium, or carbon) in a restricted range of $\mathrm{UO}_{2}$ sizes and fuelto-moderator ratios.

One way to illustrate this interesting characteristic is shown in Fig. A1, in which the critical mass of a single unit of uranium is plotted against the enrichment of ${ }^{235} \mathrm{U}$ in the uranium. ${ }^{17}$ The critical mass of uranium increases monotonically with decreasing enrichment, and at about $6 \%{ }^{235} \mathrm{U}$, the critical mass increases without limit. This limiting enrichment is independent of the character of the reflector and the form of the uranium (metal or oxide).

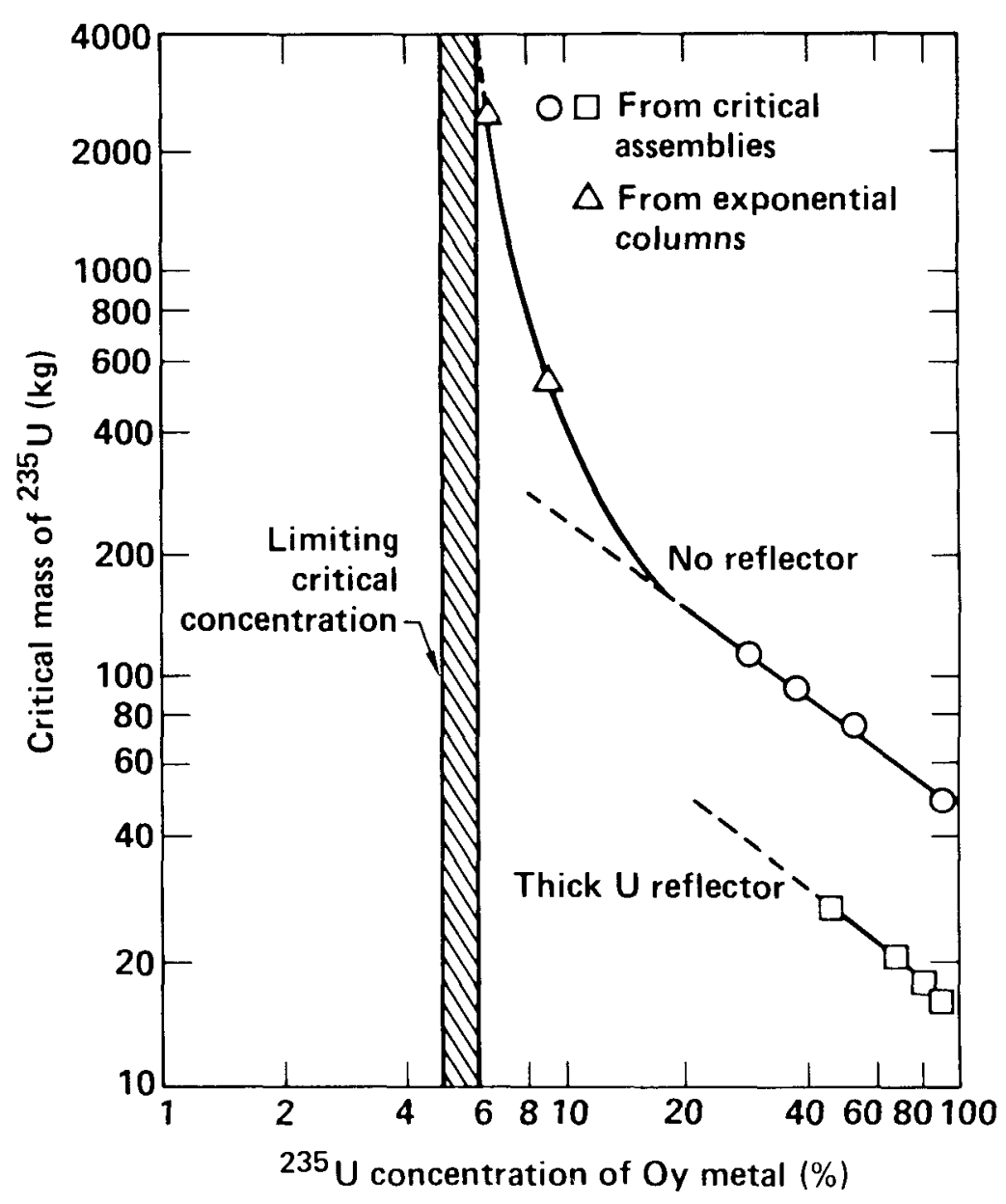

Figure A1. Critical mass vs ${ }^{235} \mathrm{U}$ concentration of enriched uranium. The shaded strip represents the range of uncertainty in the value of ${ }^{235} \mathrm{U}$ concentration below which uranium metal cannot be made critical. 
The same characteristic is shown in Figs. A2 and A3. In these figures, the $k_{\infty} \mathrm{s}$ of infinite arrays of $\mathrm{UO}_{2}$ spheres enriched to 2 and $3 \%{ }^{235} \mathrm{U}$ are plotted against the diameters of the spheres. The parameters are the volume fraction of water and soluble boron concentration. In each case, as the sphere size increases from very small diameters-or a homogeneous mixture-to larger diameters, the multiplication factor $\left(k_{\infty}\right)$ increases a few percent, and then drops to a subcritical value when the spheres become large enough $(2-20 \mathrm{~cm}$, depending on the volume fraction of water and the boron concentration). Thus, even an infinite array of $3 \%$ enriched solid $\mathrm{UO}_{2}$ spheres cannot be made critical if the sphere diameters are more than a few centimeters.

This same characteristic is illustrated in Fig. A4. This is an infinite array of $3 \%$ enriched fuel pins, shown as a function of lattice spacing, boron content, and the presence or absence of cladding. In every case, as the lattice pitch is decreased and water moderation is lessened, the $k_{\infty}$ decreases to subcriticality. In effect, as the pitch is decreased, the system looks more like a solid.

Clearly then, some size (a diameter or pin structure), moderation (water), and mixing are necessary for slightly enriched $(<6 \%)$ uranium to become critical. The criteria of spacing, size, moderation, and poison content become more restrictive as the enrichment decreases, but

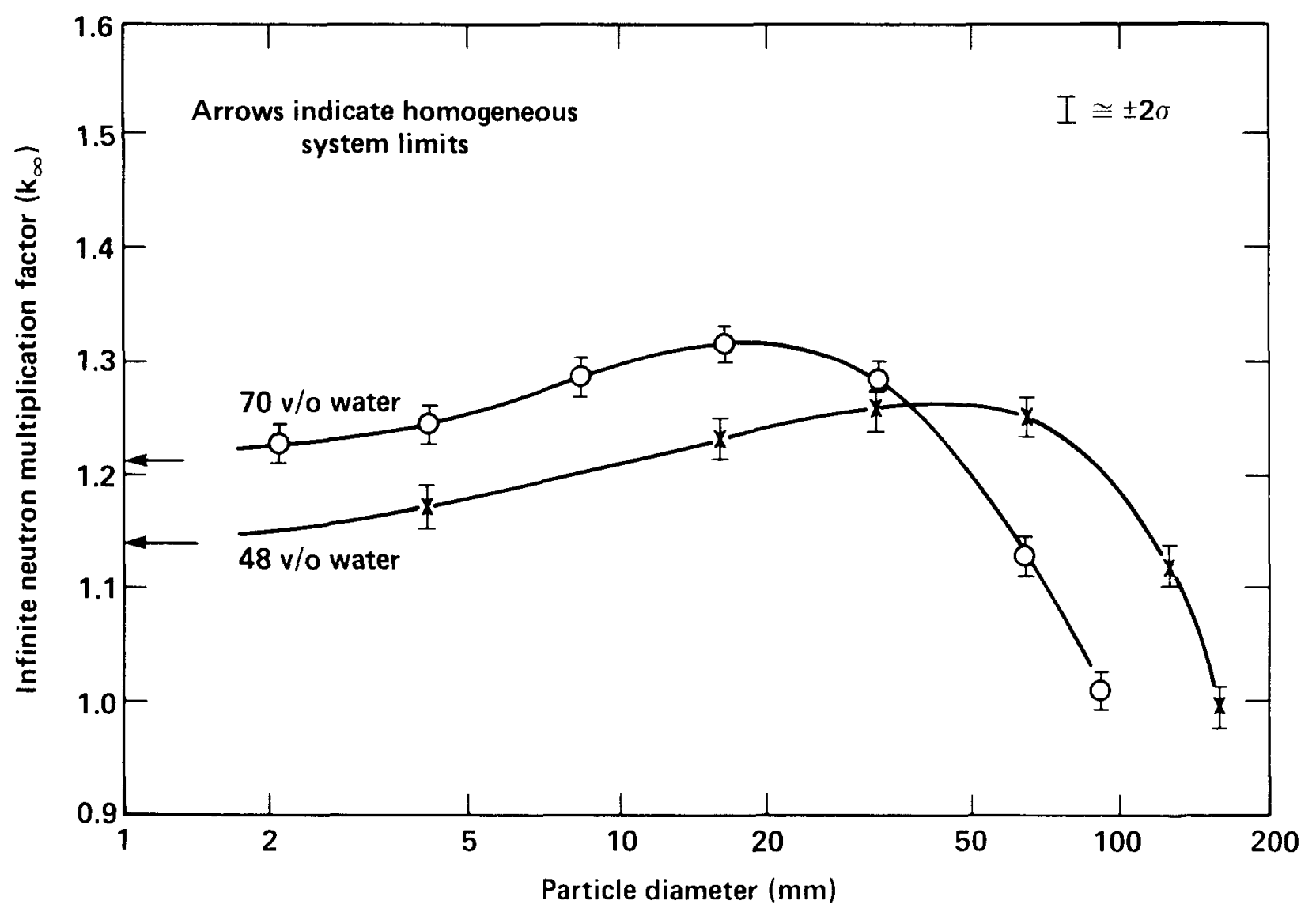

Figure A2. Effect of spherical fuel pellet diameter and fuel/water volume fraction $(\mathrm{v} / \mathrm{o})$ on the $k_{\infty}$ for $2 \%$-enriched $\mathrm{UO}_{2}$. The fuel pellets are centered in water-filled cubic cells with specular reflection on all faces of the cube. Fuel and water densities were 10.97 and $1.00 \mathrm{~g} / \mathrm{cm}^{3}$, respectively. 


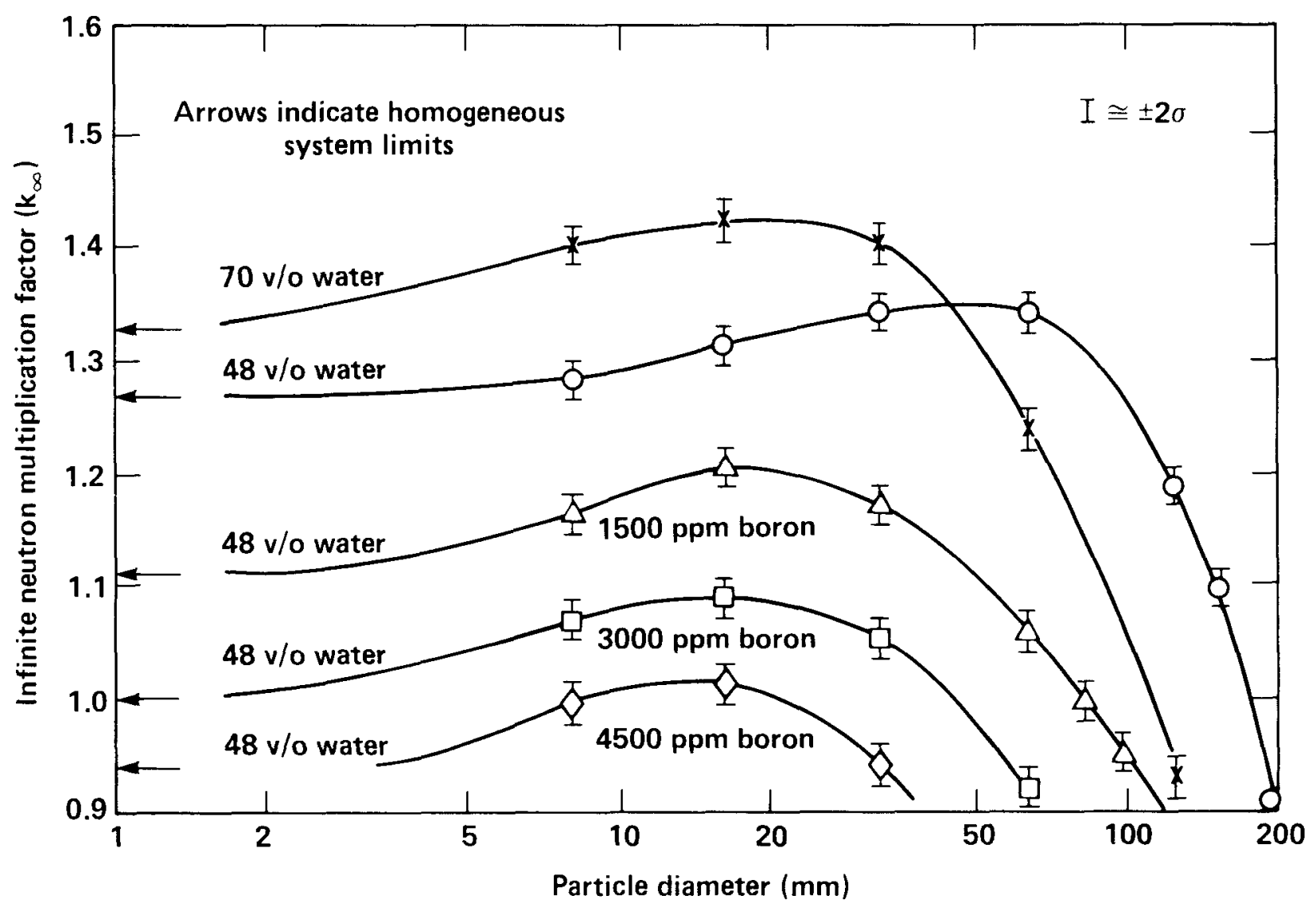

Figure A3. Effect of spherical fuel pellet diameter and fuel/water volume fraction (v/o) and boron concentration on the $k_{\infty}$ for $3 \%$-enriched $\mathrm{UO}_{2}$. The fuel pellets are centered in water-filled cubic cells with specular reflection on all faces of the cube. Fuel and water densities were 10.97 and 1.00 $\mathrm{g} / \mathrm{cm}^{3}$, respectively.

even natural uranium $\left(0.7 \%{ }^{235} \mathrm{U}\right)$ can be made critical with graphite or $\mathrm{D}_{2} \mathrm{O}$ moderation. The lower enrichment limit for water moderation is believed to be about $1 \%{ }^{235} \mathrm{U}$.

Another measure of the moderation required is illustrated in Fig. A5, in which the critical radius of a single sphere of $3 \%$-enriched $\mathrm{UO}_{2}$ mixed homogeneously with water is plotted against the ratio of hydrogen to ${ }^{235} \mathrm{U}$ atoms, which is the degree of moderation. The asymptote at the minimum moderation of about $\mathrm{H} /{ }^{235} \mathrm{U}=26.0$ corresponds to a water volume fraction of 0.23 ; i.e., the system must be more than about $23 \%$ water to become critical, regardless of the amount of uranium present. The reactivity of pins or small spheres of $\mathrm{UO}_{2}$ is greater than the homogencous mixture, as illustrated in Figs. A2 and A3, but only by a few percent. Thus, even a configuration of pins or spheres (or rubble) would require more than about $20 \%$ pure water by volume to achieve criticality. For this reason, the TMI-2 core could not achieve criticality in an environment of steam at atmospheric pressure. 


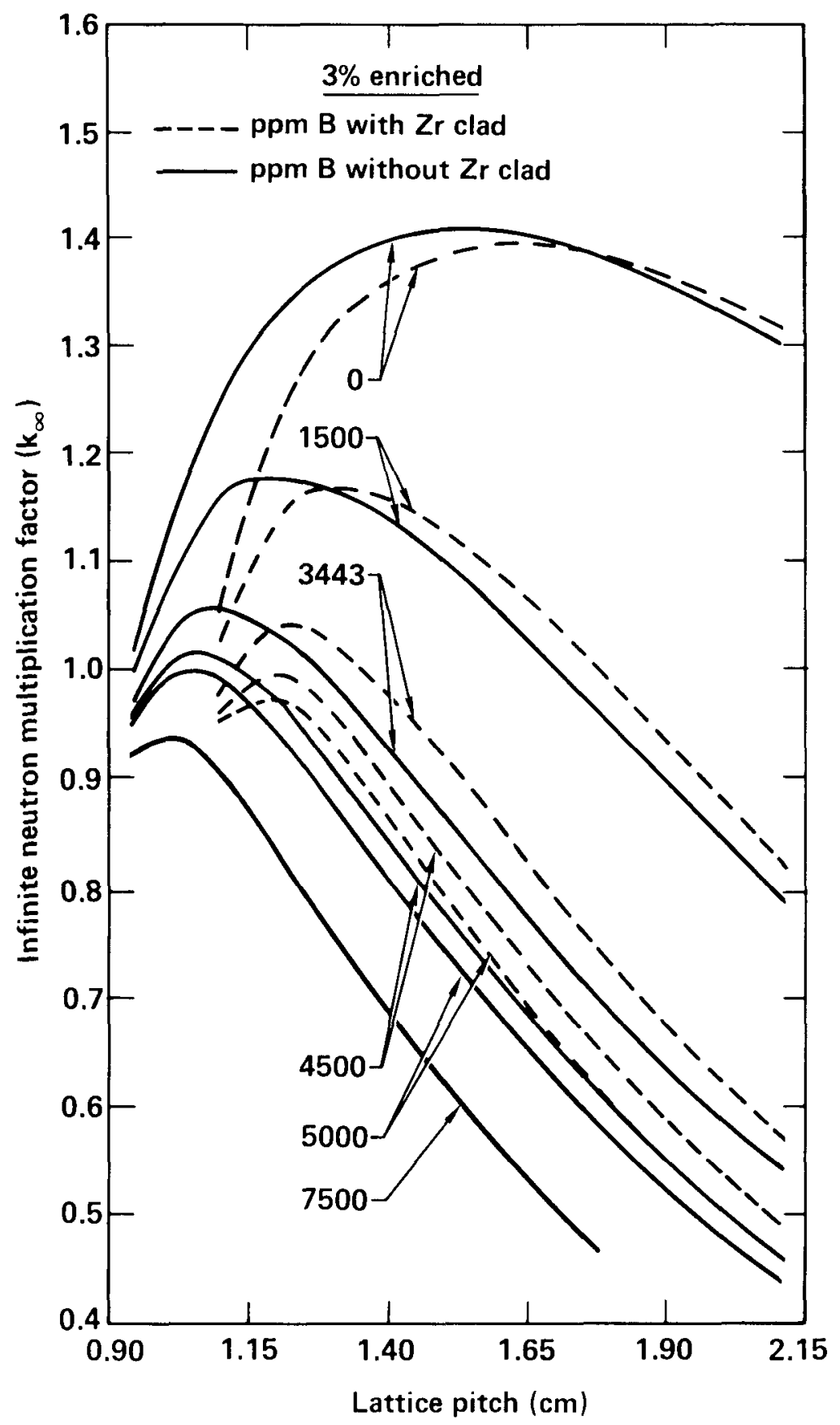

Figure A4. The infinite neutron multiplication factor $k_{\infty}$ for arrays of $3 \%$-enriched $\mathrm{UO}_{2}$ fuel pins with and without zirconium cladding for different boron concentrations and variable lattice pitch. The standard lattice pitch for an intact core is $1.44 \mathrm{~cm}$. 


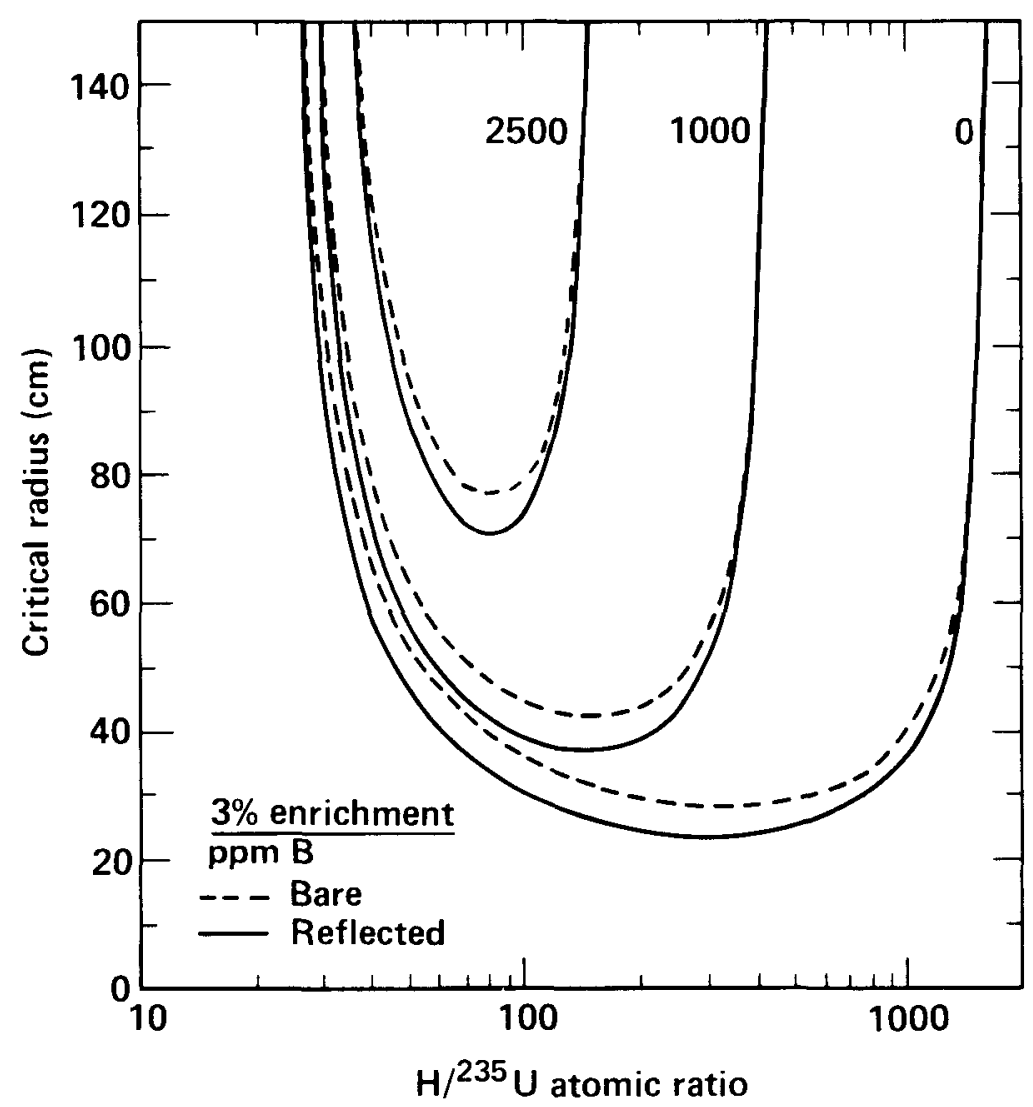

Figure A5. Effect of various boron concentrations on the critical radius for $3 \%$-enriched homogeneous $\mathrm{UO}_{2}$ /water spheres as a function of $\mathrm{H} /{ }^{235} \mathrm{U}$ atomic ratios.

The very strong poisoning effect of boron is also illustrated in these figures. Additional data from Ref. 18 (not illustrated) show that a homogeneous mixture of water and $\mathrm{UO}_{2}$ enriched to $3 \%{ }^{235} \mathrm{U}$ cannot be made critical if the boron concentration is greater than $4000 \mathrm{ppm}$. This limit corresponds well with the limiting concentration of $4300 \mathrm{ppm}$ derived in Appendix B for $3 \%$-enriched pins. The fact that an array of pins can be somewhat more reactive than a homogeneous mixture is illustrated again. 


\section{Appendix B Analytical Models and Computational Results}

Because of the uncertainty in our knowledge of the TMI-2 core configuration, the particle size, and the mixture of steel, zircalloy, zirconium oxide, poison rods, and $\mathrm{B}_{4} \mathrm{C}$ pellets, the evaluation of core reactivity must proceed with conservative assumptions when unknown factors are encountered. A number of conservatisms exist in all these studies, and are mentioned here when appropriate. Nevertheless, the objective of this appendix is to evaluate the reactivity as realistically as possible, allowing for unknown conditions. The most conservative model (the licensing model) and the simplest model (the infinite model) are examined first; subsequent models are more realistic.

\section{The Licensing Model ${ }^{6}$}

In 1984, an infinite poison concept was adopted. Rather than analyze each possible rearrangement of material during fuel removal, the soluble boron concentration was increased significantly, from around $3500 \mathrm{ppm}$ to around $5000 \mathrm{ppm}$ (the license value is to be $4350 \mathrm{ppm}$ ), to render the fuel subcritical under every conceivable condition. To determine the licensing boron concentration, a series of calculations was performed by ORNL. These analyses used both XSDRNPM and KENO Va for the complex geometric model. This analytical program had two parts: (a) the calculation of the effective multiplication factor $\left(k_{\mathrm{eff}}\right)$ for optimized arrangements of fuel and water moderator, and (b) the computer code benchmarking described in Appendix $\mathrm{C}$ of this report.

The assumed physical arrangement of the fuel in the model is conservative, and even incredible in several respects. Most of these conservatisms are listed below:

- Fuel mass is located in the lower vessel head;

- The entire core fuel mass is used;

- The model has a lenticular shape.

- The highest enrichment fuel is placed in the center of the model;

- A steel reflector is used;

- Rubble model size and shape are optimized;

- No cladding or structural materials are included;

- No solid poisons are included;

- Fuel-to-moderator ratio is optuimized;

- No burnup credit is given in the lower enrichment fuel;

- Boron concentration is 4350 ppm;

- Computational bias is $2.5 \%$.

By determining that such a conservative model is subcritical, it is certain that the actual system will not become critical, regardless of the defueling operations performed. As determined by this calculation, $k_{\text {eff }}$ is less than 0.99 for a boron concentration $>4350 \mathrm{ppm}$.

After completion of this study, the first remote video examination of the lower reactor vessel head was completed in April 1985. This examination showed that as much as 1000-2000 $\mathrm{kg}$ of fuel, zircalloy, and steel could have become liquefied and flowed to this region of the vessel where it solidified and crumbled into large pieces. Because the neutron multiplication of an array of picces of centimeter-sized fuel spaced for optimum moderation can be more reactive than a rubble bed, the licensing model (which did not consider fuel melting) has been modified, and more calculations have been completed. 
The modified model assumes that:

- $30 \%$ of the fuel consisted of $3.5-\mathrm{cm}$ spheres at the average core enrichment (2.57\%), spaced for optimum moderation, and placed at the center of the lenticular model. (This was determined to be the optimum size.)

- This fuel was surrounded by $70 \%$ of the $3 \%$-enriched, rubblized fuel at optimum moderation.

- The structure was then surrounded by the remainder of the fuel, rubblized and at optimum moderation.

- The configuration was placed in the lower vessel head and reflected by the steel of the vessel.

- The boron concentration was fixed at $4350 \mathrm{ppm}$

The neutron multiplication of this modified model was found to be about the same as the original licensing model described above. The licensing model has been reviewed and approved by the NRC.

\section{Infinite Configurations}

A useful concept in the evaluation of criticality safety problems is the multiplication factor of the infinite system, denoted as $k_{\infty}$. The concept as applied to a reactor assumes the fuel pins to be unlimited in length and the number of pins to be unbounded in the radial direction - i.e., the system is replicated indefinitely in all directions. It should be obvious that the multiplication of the finite system $\left(k_{\text {eff }}\right)$ will be less than the $k_{\infty}$ value, because the infinite system has no leakage. Parametric studies of this type have been completed by Thomas et al. at the Oak Ridge National Laboratory, ${ }^{19}$ and by McLaughlin at the Los Alamos National Laboratory. ${ }^{18}$

\section{The Oak Ridge Model ${ }^{8}$}

The Oak Ridge National Laboratory model consisted of an infinite set of water-moderated fuel pins with and without cladding, of $2,2.57$, and $3 \%$ enrichment, and with variable lattice spacing. The boron concentration was varied from zero to $4500 \mathrm{ppm}$ for all enrichments, and up to $7500 \mathrm{ppm}$ for $3 \%$-enriched pins. This very large body of data is summarized in Figs. $\mathrm{B} 1-\mathrm{B} 4$. The first three figures show the $k_{\infty}$ for $2,2.57$, and $3.0 \%{ }^{235} \mathrm{U}$, various boron concentrations, with and without cladding, and with a variety of spacings between pins (called the 'pitch'). No structural materials, fixed poisons, or fuel burnup are included.

Figure B4 shows the maximum $k_{\infty}$ for each enrichment plotted against the boron concentration. In this figure, it can be seen that for $2 \%{ }^{235} \mathrm{U}$ with cladding, $k_{\infty}=1.0$ at about $2000 \mathrm{ppm}$ boron; and $k_{\infty}(2.57 \%)=1.0$ at about 3400 ppm boron. The present boron concentration is between 4950 and $5200 \mathrm{ppm}$; thus at these boron concentrations, the calculations indicate the system would be subcritical even if composed of unclad pins of $3 \%$-enriched fuel.

The $k_{\infty}$ chosen for Fig. B4 are the maxima for any pin spacing or pitch (the design pitch is $1.443 \mathrm{~cm}$ ). The actual rubble has no "pitch," but the observed moderator-to-fuel ratio is better represented by a pitch of about 1.05-1.10. The $k_{\infty}$ for $3 \%$ fuel with and without cladding can be read from Fig. B3 at a pitch of $1.09 \mathrm{~cm}$, and then plotted on Fig. B5 as a function of boron concentration. The slopes are different from each other and from those on Fig. B4. The pin arrays with cladding are subcritical for boron concentrations greater than about $2200 \mathrm{ppm}$, but the array without cladding is about the same as in Fig. B4. The importance of this figure is to show that as the pitch is decreased from the design pitch, the difference increases between the $k_{\infty}$ with and without cladding. This effect can be attributed to a decreased water volume fraction, 


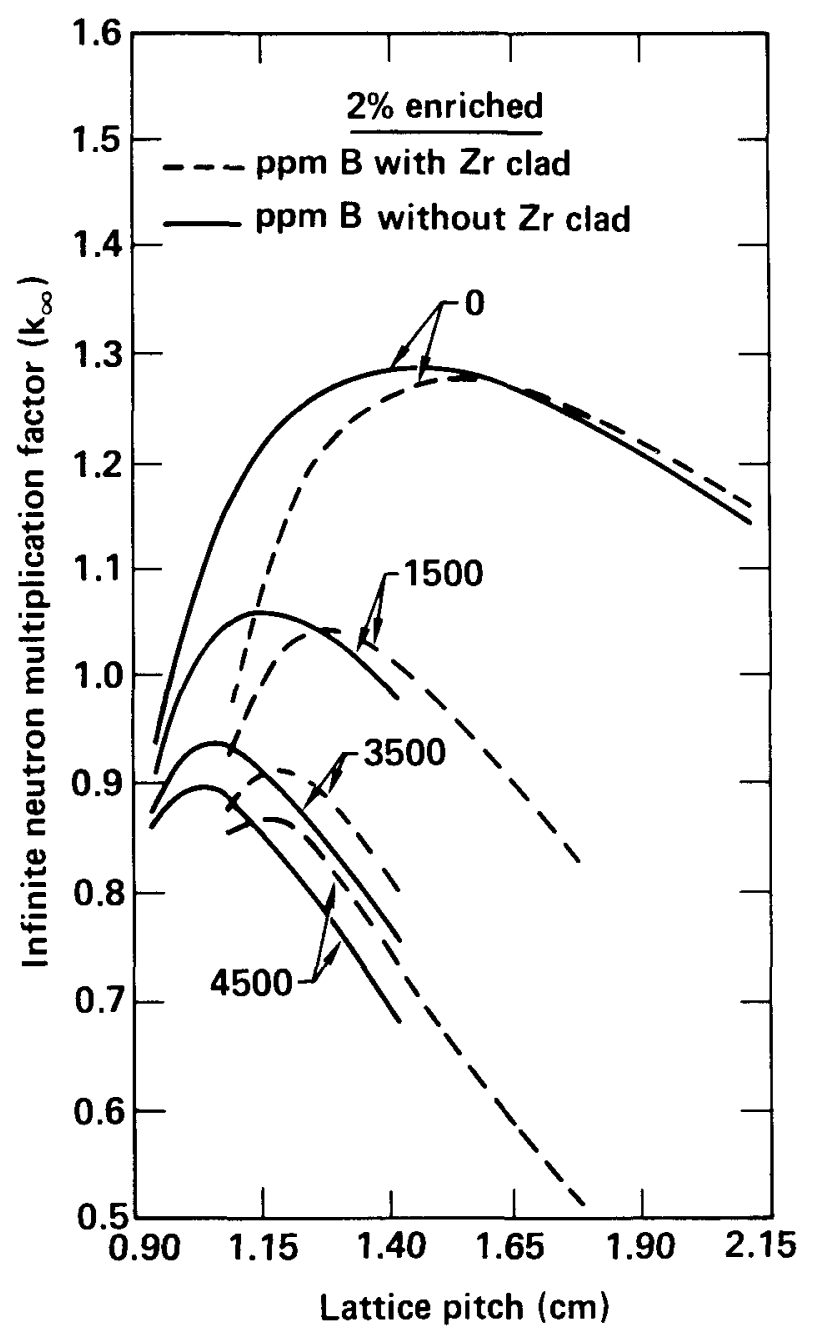

Figure B1. The infinite neutron multiplication factor $k_{\infty}$ for arrays of $2 \%$-enriched $\mathrm{UO}_{2}$ fuel pins with and without zirconium cladding for different boron concentrations and variable lattice pitch. The standard lattice pitch for an intact core is $1.44 \mathrm{~cm}$.

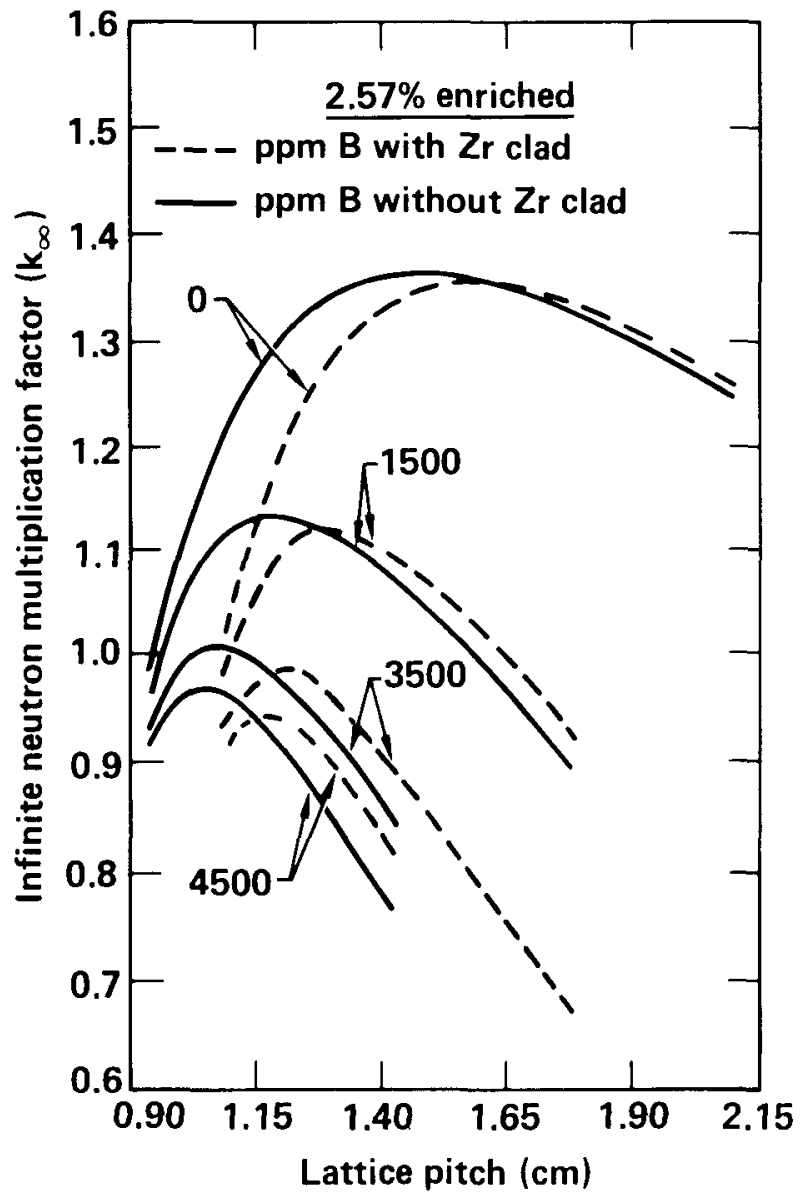

Figure B2. The infinite neutron multiplication factor $k_{\infty}$ for arrays of $2.57 \%$ enriched $\mathrm{UO}_{2}$ fuel pins with and without zirconium cladding for different boron concentrations and variable lattice pitch

and hence less moderation, for the case with cladding; this would be exaggerated even more for a pitch of 1.05 .

For a boron concentration of $4350 \mathrm{ppm}$, pins of average enrichment $(2.57 \%)$, and with cladding, the $k_{\infty}$ can be read from Fig. $\mathrm{B} 4$ to be 0.95 . Another estimate can be obtained from the lower curve of Fig. B5 after correcting for the difference between $k_{\infty}$ (3.0) and $k_{\infty}$ (2.57). From Fig. B4, this appears to be 0.05 . Using these two steps, the $k_{\infty}$ for a pitch of $1.09 \mathrm{~cm}$ is $0.96-0.05$ $=0.91$. Both values are conservative in that no structural material, poison, or fuel burnup is considered, and the calculation is for an infinite system. These results are summarized in Table B1. 


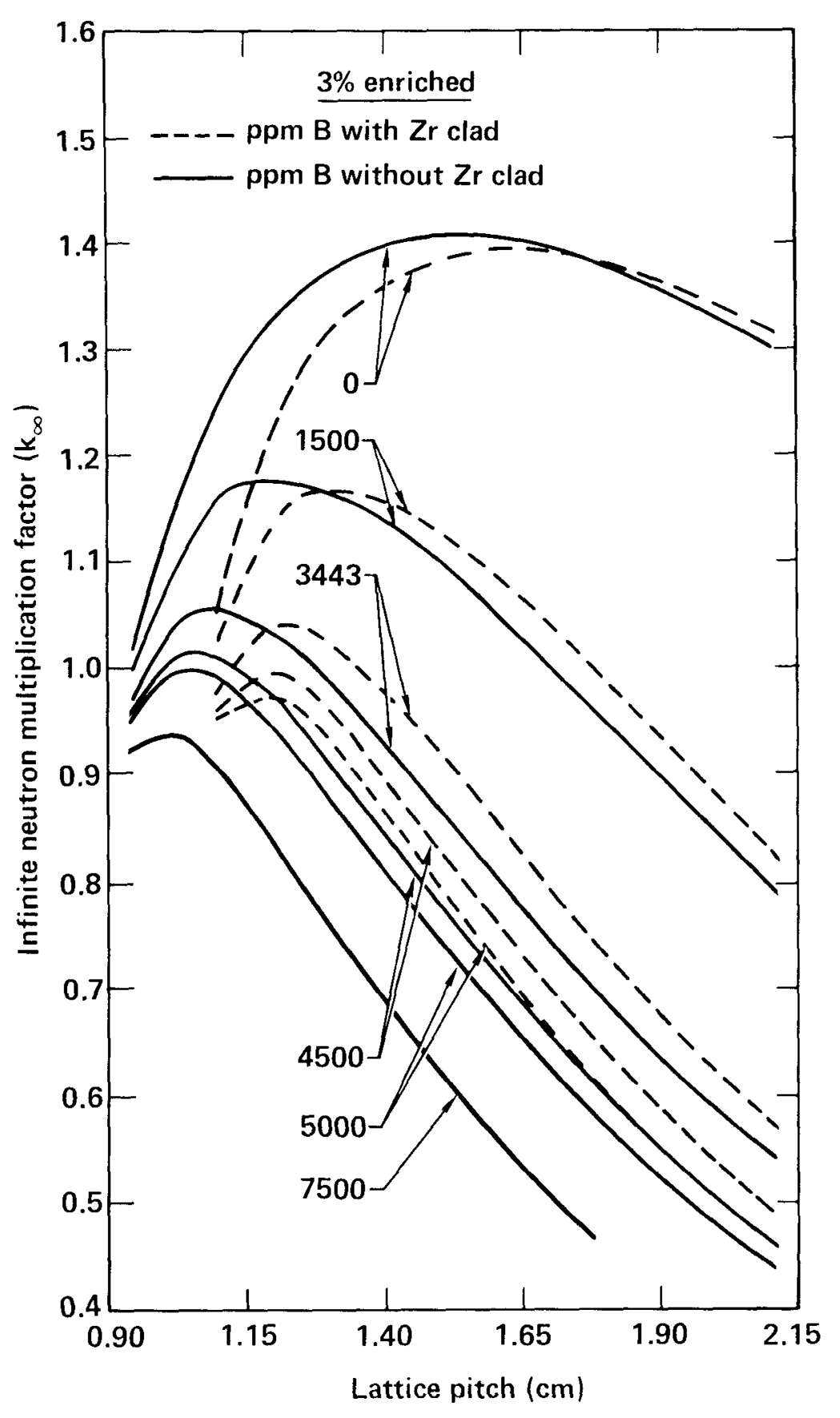

Figure B3. The $k_{\infty}$ for arrays of $3 \%$-enriched $\mathrm{UO}_{2}$ fuel pins with and without zirconium cladding for different boron concentrations and variable lattice pitch. 


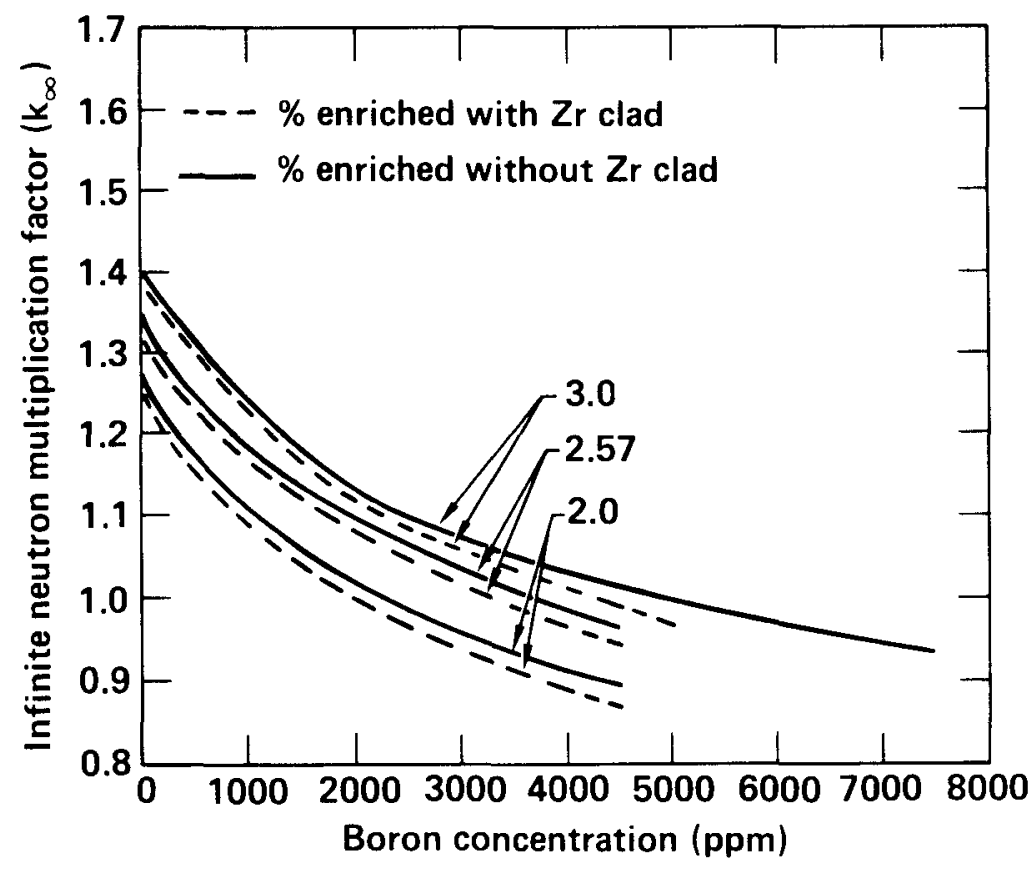

Figure B4. Comparison of the maximum calculated $k_{\infty}$ for infinite systems of 2-, 2.57-, and $3 \%$-enriched $\mathrm{UO}_{2}$ fuel pins with and without zirconium cladding as a function of the boron concentration in the moderator.

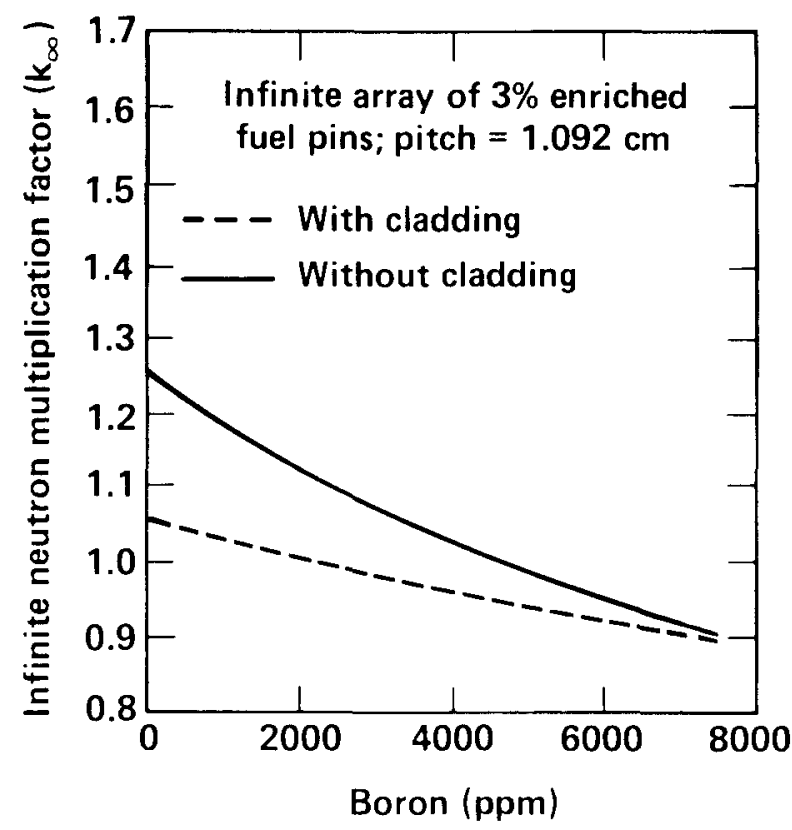

Figure B5. Comparisons of the maximum $k_{\infty}$ for systems of $3 \%$-enriched $\mathrm{UO}_{2}$ fuel pins with and without zirconium cladding at a pitch of $1.092 \mathrm{~cm}$ as a function of the boron concentration in the moderator. 


\section{The Los Alamos Model ${ }^{7}$}

The Los Alamos National Laboratory model is an array of $\mathrm{UO}_{2}$ spheres, enriched to 2 or $3 \%{ }^{235} \mathrm{U}$ with a constant water-volume fraction of 0.48 (and one series with 0.70 water by volume), which is replicated indefinitely. No cladding, structural material, fixed poison, or fuel burnup are included. These calculations were performed using the Los Alamos Monte Carlo Neutron Photon Code (MCNP), 15 using the ENDF-B/V cross-sections directly. The data are illustrated in Figs. B6 and B7. The data in these figures show that for each boron concentration and moderator volume fraction, the $k_{\infty}$ increases slightly as the fuel particle diameter is increased. In each case, the maximum multiplication factor reached is a few percent higher than the value for the homogeneous mixtures. The optimum diameter is between 1.5 and $8 \mathrm{~cm}$, depending on boron concentration; as the size is increased further, the $k_{\infty}$ decreases to subcritical values.

The data in Fig. B6 can be treated as were the data in the ORNL model, the infinite assembly of pins. If the maximum $k_{\infty}$ for each curve of Fig. B6 is plotted on Fig. B4, the two sets of data are remarkably similar for the boron concentrations of interest, considering the different models, different Monte Carlo codes, and different cross-section sets.

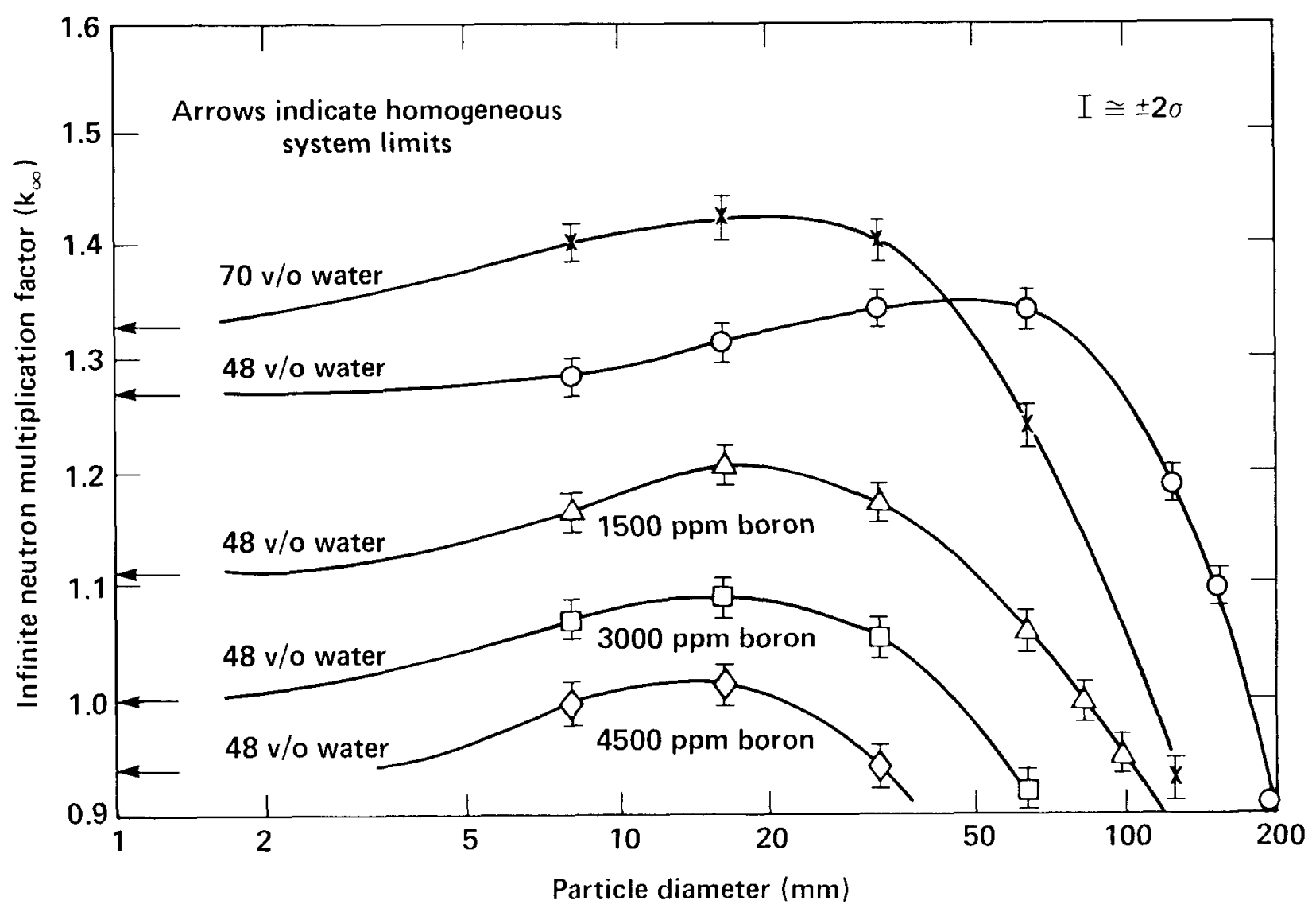

Figure B6. Effect of spherical fuel pellet diameter and fuel/water volume fraction (v/o) on the $k_{\infty}$ for $3 \%$-enriched $\mathrm{UO}_{2}$. The fuel pellets are centered in water-filled cubic cells with specular reflection on all faces of the cube. Fuel and water densities were 10.97 and $1.00 \mathrm{~g} / \mathrm{cm}^{3}$, respectively. 


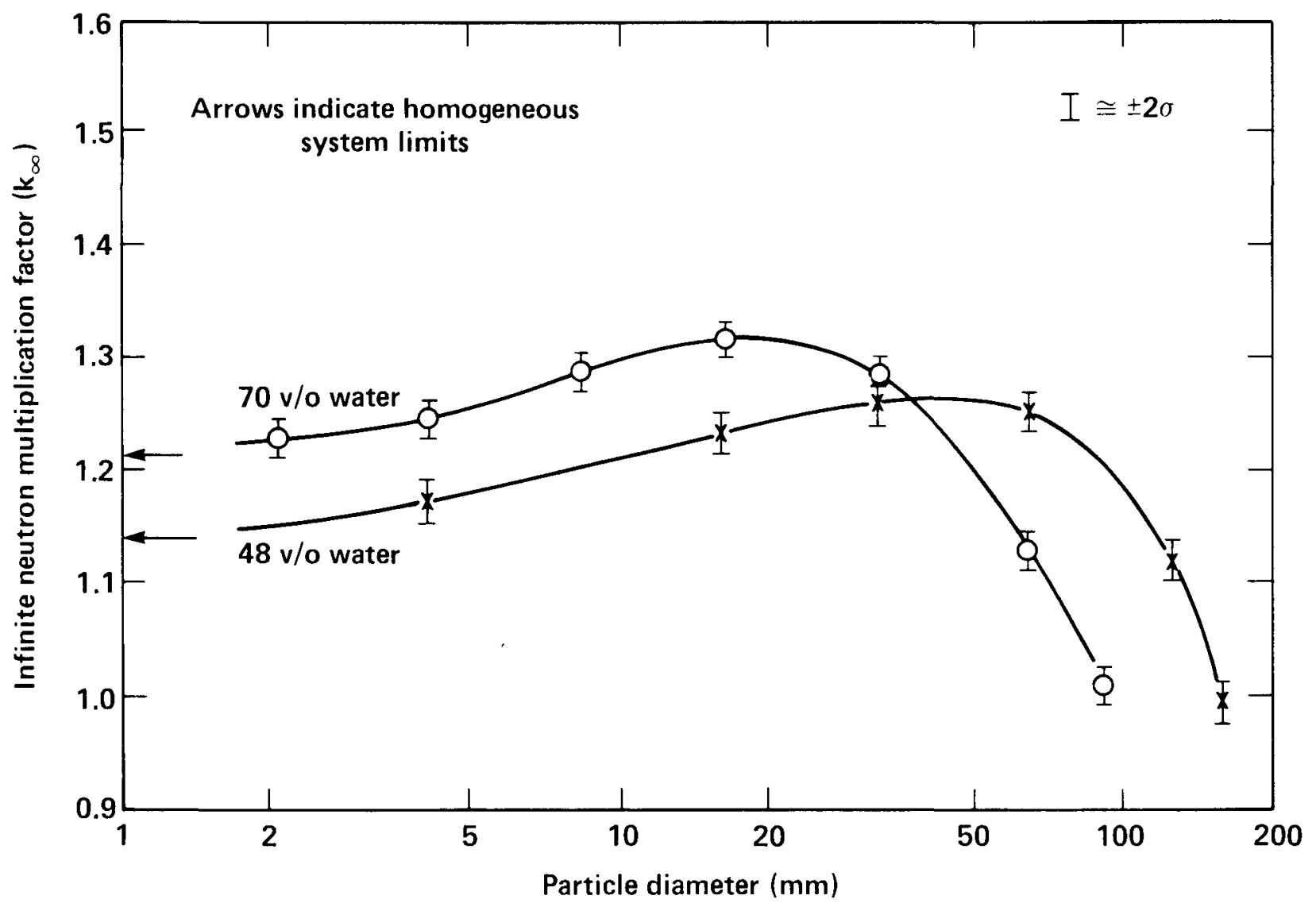

Figure B7. Effect of spherical fuel pellet diameter and fuel/water volume fraction (v/o) and boron concentration on the $k_{\infty}$ for $2 \%$-enriched $\mathrm{UO}_{2}$.

Note that this study was begun independently of the modifications to the licensing model discussed above. The agreement between these two studies provides confidence in the results, and confidence that the existing system is indeed substantially subcritical. These results are summarized in Table B1.

The results suggest that $k_{\infty}>1.0$ for two cases. This does not in reality indicate a critical condition, however; the reactor core is not a regular infinite system, it is not $3 \%$ enriched throughout and, in addition to other conservatisms, leakage from the system would lower the neutron multiplication by several percent.

\section{Finite Configurations}

To calculate realistically the reactivity of a fissile system, a model must closely describe the actual configuration, and the computer code must be able to accommodate the actual geometry. The TMI-2 core is a cylinder, but the internal composition (i.e., the size of rubble and fused components, presence of poison, or possible voids) is not well known. Consequently, assumptions have been made where only partial knowledge exists; these assumptions were made conservatively to assure a result that overestimates the reactivity.

Two models were developed by the ORNL group (in 1979 and 1984, respectively). Each model represents the existing system in some, but not all, characteristics. 
Table B1. Estimates of the neutron multiplication factor for infinite models $\left(k_{\infty}\right)$. Boron Concentration $=4350 \mathrm{ppm}$.

\begin{tabular}{|c|c|c|c|c|}
\hline Model & & $\begin{array}{l}\text { Cladding } \\
\text { Used }\end{array}$ & $k_{\infty}$ & $\begin{array}{l}\text { Basis for } \\
\text { Results }\end{array}$ \\
\hline ORNL & $(2.57 \%)$ & yes & 0.95 & Fig. B4 \\
\hline ORNL & $(3.0 \%)$ & yes & 0.96 & Fig. B5 \\
\hline ORNL & $(2.57 \%)$ & yes & 0.91 & $\begin{array}{l}\text { Fig. B5 (adjusted } \\
\text { for enrichment) }\end{array}$ \\
\hline ORNL & $(3.0 \%)$ & no & 1.01 & Fig. B5 \\
\hline LANL & $(3.0 \%)$ & no & 1.01 & $\begin{array}{l}\text { Fig. B } 6 \text { max. } \\
\text { plotted on Fig. B4 }\end{array}$ \\
\hline
\end{tabular}

\section{The "In-Place Core Slump" Model (1979) 2}

In 1979, it was surmised that the fuel had lost its integrity and had slumped, but the amount of fragmentation and slumping were not known. The ORNL team developed a first model using an assumption that the fuel pins and cladding had expanded radially and slumped axially, while maintaining constant density and volume. The core height was decreased and the pin structures were retained, a conservative assumption relative to a rubble bed or homogeneous model. Their attempt was to create a simple but general and conservative model of core collapse. The boron concentration used in the calculation was $3180 \mathrm{ppm}$, and fuel burnup was not considered.

The calculated neutron multiplication factors for different core heights are presented in a table format in Ref. 2 and illustrated in Fig. B8. Control rods and burnable-poison rods are modelled as being in their normal locations, and the fuel is the core average enrichment of $2.57 \%$. The initial effect of compressing the core is an increase in reactivity, with a maximum reached at about $7-1 / 2$ feet $\left(k_{\text {eff }}=0.848\right)$. The change in $k$ is a balance between squeezing out boron (a poison) and hydrogen (a moderator and mild poison), and increasing the neutron leakage by making the system smaller. The direction and amount of this change for the several variables is not obvious and can be obtained only through the use of a reactivity calculation. Eventually, however, as the core is compressed further, the loss of hydrogen moderation must cause the reactivity to decrease, since low-enriched $\mathrm{UO}_{2}$ cannot be made critical without a neutron moderator, and any poison in the system merely enhances this effect.

Reference 2 shows that the control rods and burnable-poison rods were worth $\Delta k=0.082$ for a boron concentration of $3180 \mathrm{ppm}$ and with the core in its normal configuration. If this value is added to the maximum of Fig. B8, the resulting $k_{\text {eff }}$ for this "squashed" system without any fixed poison (but with cladding), would be 0.93. Insofar as such a squashed set of pins may represent the rubble (about $7 \mathrm{ft}$ high), this result suggests that the core may have been far subcritical at $3180 \mathrm{ppm}$. Generally, for power reactor fuel, a pin structure is more reactive than a more homogeneous mixture of the same size and mass, and the $k_{\text {eff }}=0.93$ may be a slight overestimate. 


$$
\text { ) }
$$

the remaining seven feet of pins, one-third was placed below. The rubble contained no cladding, structural material, or solid poison, and its density was assigned at $5.34 \mathrm{~g} \mathrm{U}_{3} \mathrm{O}_{8} / \mathrm{cm}^{3}$, about the density value for maximum $k_{\infty}$. The remaining pin structure retained its cladding and was treated both with and without control rods. Burnup was not included here.

As more of the core is assumed to be rubble, the model calculations predict a monotonically increasing $k_{\text {eff, }}$ as illustrated in Fig. B9 for three boron concentrations. The endpoints (for no intact fuel) represent a fully rubblized core, mixed to an average enrichment of $2.57 \% 235 \mathrm{U}$, with no control or burnable poison material, cladding, or structural material remaining. The calculated $k_{\text {eff }}$ is 0.941 for 3500 ppm boron, and 0.906 for 4500 ppm boron, values believed to be very conservative. Cladding has been seen in the rubble, core structural material is present, some poison $\left(\mathrm{B}_{4} \mathrm{C}\right)$ pellets remain, and some control-rod material may exist.

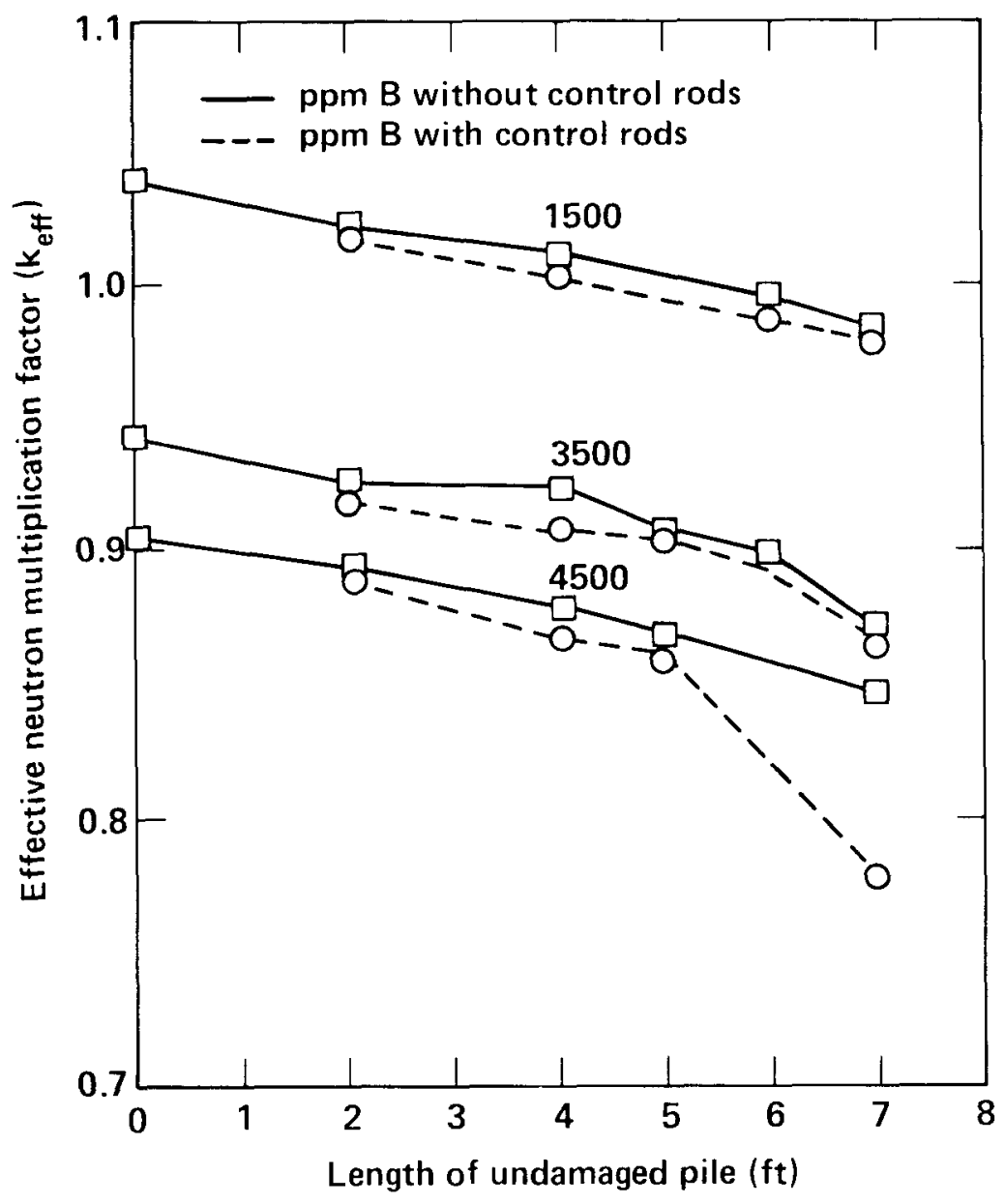

Figure B9. Calculated $k_{\text {eff }}$ for the 1984 ORNL model as a function of the remaining intact fuel assembly height for three boron concentrations. The rubblized fuel is assumed to be core average enrichment and is distributed with $2 / 3$ of the rubble above the remaining fuel pins and $1 / 3$ below. The rubble does not contain cladding, poison, or structural material. 
However, using the average enrichment begs the question of $k_{\text {eff }}$ for the rubblized core with fuel remaining in its original radial position (i.e., $1.98 \%$ fuel collapsing upon itself, $2.96 \%$ fuel remaining at the perimeter, etc.). This has been calculated for the intermediate rubblized case of six feet (i.e., half of the core) of remaining pin structure and six feet reduced to rubble. The $k_{\text {eff }}$ for 3500 ppm boron was 0.894 , essentially the same as the $k_{\text {eff }}(=0.889)$ for the case with rubble mixed to an average enrichment of $2.57 \%$. Thus, the average enrichment throughout is apparently a reasonable representation of the core with fuel in its original radial position.

The model also does not address a more unfavorable distribution of enrichment, such as the $2.96 \%$-enriched fuel somehow placed in a more-reactive position in or near the center of the core. Because this rearrangement cannot be created by any reasonable realistic sequence of events, a very conservative assumption is to assume that the whole core is composed of fuel that is enriched to $3 \%{ }^{235} \mathrm{U}$ (the maximum enrichment is actually $2.96 \%$ ). This has been completed with $3500 \mathrm{ppm}$ boron for the rubblized case, with a $k_{\text {eff }}$ computed to be 0.984 . The conservatisms mentioned above apply to this case as well. This result provides additional confidence because $k_{\text {eff }}$ is less than 1.0 and derives from very conservative assumptions. These rubble bed estimates are for a model without cladding material mixed in. An estimate of this effect (lesser moderation at the same volume) can be obtained from Fig. B5. For a boron concentration of $4350 \mathrm{ppm}$ and a pitch of $1.09 \mathrm{~cm}$, the effect is $\Delta k=0.055$. Table B2 gives the collected data for these 1984 rubblized model cases.

Table B2. Estimated neutron multiplication factor $\left(k_{\text {eff }}\right)$ for finite models. Boron concentration $=4350 \mathrm{ppm}$.

\begin{tabular}{lccc}
\hline Model & $\begin{array}{c}\text { Cladding } \\
\text { Used }\end{array}$ & $k_{\text {eff }}$ & $\begin{array}{c}\text { Basis for } \\
\text { Results }\end{array}$ \\
\hline $1979(2.57 \%)$ & yes & 0.91 & $\begin{array}{c}\text { Fig. B5 extrapolation } \\
\text { Fig. B5 extrapolation } \\
\text { above } k_{\text {eff }} \text { corrected for } \\
\text { cladding }\end{array}$ \\
$1984(2.57 \%)$ & no & 0.91 & $\begin{array}{c}\text { Fig. B5 extrapolation } \\
\text { above } k_{\text {eff }} \text { corrected for } \\
\text { cladding }\end{array}$ \\
$1984(3.57 \%)$ & yes & 0.86 & \\
$1984(3.0 \%)$ & no & 0.95 &
\end{tabular}

These estimates can be adjusted further for effects mentioned in the text.

Fuel burnup: -0.018

Fuel clumping: about 0.02

Solid boron carbide remaining in the rubble: unknown, but up to -0.05

Computational bias: \pm 0.02 , assume +0.02

These data can be plotted on Fig. B5 as a function of boron concentration to obtain the multiplication factor for the case with $4350 \mathrm{ppm}$ boron. Because the core of a modern nuclear electric power station is so large, its response to small changes in parameters, say ${ }^{235} \mathrm{U}$ enrichment or boron concentration, is not unlike the response of the infinite system. Thus, interpolations and extrapolations parallel to the $k_{\infty}$ plots (without cladding in this case) are 
acceptable for small changes. From these interpolations and extrapolations, the multiplication factors for these finite models can be estimated at $4350 \mathrm{ppm}$ boron. For $2.57 \%$-enrichment throughout and for 3\% throughout, the estimated multiplication factors are 0.91 and 0.95 , respectively. If the correction for cladding is included, the multiplication estimates are 0.86 and 0.90. These data are also included in Table B2.

This technique can provide other criticality data. The margin of boron concentration to the critical state, for example, can be found. From Fig. B5, for the postulated 3.0\% core without cladding, the boron concentration would have to drop to about $3400 \mathrm{ppm}$ for criticality. (The boron concentration would be much less for the case with cladding). For the $2.57 \%$ core, boron concentration would have to drop to $2250 \mathrm{pm}$ to achieve criticality. Also, the TMI-2 reactor has been subcritical since the accident, even with a boron concentration of $3000 \mathrm{ppm}$, or possibly less.

\section{Summary of Model Results}

In conclusion, using the calculations completed in 1979 and additional subsequent studies, the TMI-2 core has been shown to be subcritical by a substantial margin with the present boron concentration.

- The licensing model shows that the reactor is subcritical even with a number of conservative assumptions. The $k_{\text {eff }}<0.99$ for any configuration if the boron concentration is $4350 \mathrm{ppm}$ or more. Modifications to allow for larger fuel particles have been incorporated.

- Recent work includes very extensive $k_{\infty}$ calculations of fuel pins at various lattice spacings, enrichments, and boron content. The $k_{\infty}$ for fuel pins of average enrichment (2.57\%) with cladding intact is only 0.96 for $4350 \mathrm{ppm}$ boron. An estimate using a better value of water content is even lower, only 0.91 . The conservative bias for these $k_{\infty}$ results was judged to be several percent.

- The $k_{\infty}$ calculations for 2- and 3\%-enriched spheres of various sizes, moderation, and boron poisoning have been completed to compare with the pin studies. Different Monte Carlo codes and cross-section sets were used. The two studies agree reasonably well for the boron concentration of interest.

- The 1979 study of the collapsing pin structure can be applied to the present condition. From this study, the $k_{\mathrm{eff}}$ was calculated to be 0.93 for a boron concentration of $3180 \mathrm{ppm}$ and estimated to be less than 0.91 for $4350 \mathrm{ppm}$.

- A model was developed that provides for a parametric study of the core with progressively greater amounts of fuel converted to rubble. This model (with conservative assumptions) shows that the $k_{\text {eff }}$ of the finite system increases monotonically with increasing amounts of the core changed to rubble. For those cases fully converted to rubble, and with $4350 \mathrm{ppm}$ boron, the model gave the following results for the multiplication factor:

Average enrichment throughout without cladding: $k_{\mathrm{eff}}=0.91$.

Artificial case of requiring all fuel to be $3 \%$ enriched without cladding: $k_{\mathrm{eff}}=0.95$.

Average enrichment with cladding, $k_{\mathrm{eff}}=0.86$. 
The conservatisms in this rubble model include: no structural material, burnable poison, or control rod material. The density of the rubble was chosen for the most reactive case.

These criticality evaluations of several models of the TMI- 2 core show that, even with very conservative assumptions, the core is subcritical by $10-15 \%$. The exact value is not known and cannot be determined exactly because of the unknown details of the fuel particle size, distribution, cladding, structural material, and poison. However, the overwhelming conclusion is that, so long as the boron content is held at $4350 \mathrm{ppm}$, the fuel will be subcritical; this substantial reactivity margin below critical allows complete freedom in the process of removing fuel. 


\section{Appendix C Computer Code Benchmarking}

Assessments of the TMI-2 core damage generally concluded that the spacing of the fuel is reduced, ${ }^{2-5}$ and thus neutron moderation is less than in the intact design core. Boron has been added since the accident, yielding an absorption that significantly exceeds normal operating levels. The core configuration as it exists, or as it might become during disassembly, tends to lie outside the region of usual application of these computer codes, both those used for reactor design or those used for nuclear criticality studies, but the configuration does not present any extraordinary or unusually difficult challenge to the computational techniques. Although the geometry of the core material (i.e., fuel, zircalloy, oxides, and steel) is known generally, it is unknown in detail; consequently, conservative assumptions are taken where appropriate. These latter uncertainties are greater in the estimating of neutron multiplication than are the uncertainties in the calculational technique.

Nevertheless, to support a choice of bounding soluble boron concentration, a limited benchmarking operation was carried out on the ORNL computer codes KENO-Va and XSDRNPM for the model presented in section 4 and Appendix B of this report. The exercise recognizes the methodology as specified in ANS-8.1-1983, Nuclear Criticality Safety in Operations with Fissionable Material Outside Reactors, which includes requirements for establishing the validity and areas of applicability of any calculational method used in assessing nuclear criticality safety. The effort put into the benchmarking was consistent with the intent of the Standard, in view of the present configuration of the TMI-2 system and with regard to the availability of experimental data.

The choice of experiments to use in this limited benchmarking program was based on the similarity between the fuel enrichment, the soluble boron concentration, and the amount of neutron moderation. Of particular interest was any bias (positive or negative) of the computer code results. Examination of such data for ten experiments indicated that most computational and experimental results agreed to within $\pm 1 \%$, but that $\pm 2.5 \%$ would cover all comparisons. This implied that the calculation performed using the licensing model described here in section 4 and Appendix $B$ should have about $2.5 \%$ reactivity added to be conservative. This does not imply that the theory may be in error, or that some experiments may be wrong, or that the physical description of the experiment may be inadequate for the theory; the conservative policy for this particular evaluation is to assume the maximum difference. Taking this into account, the resulting model of the damaged core was found to be at least $1 \%$ subcritical (i.e., $k_{\text {eff }}<0.99$ ).

It should be noted that the calculations described in section 4 and Appendix B were performed without the special TMI-2 benchmarking results applied. However, the computer codes used for these calculations have a world wide testing program of their own to ensure code accuracy for criticality calculations. For example, some benchmarking tests for the ORNL Monte Carlo Code can be found in Ref. 2. The Los Alamos MCNP code is widely used, and was constructed from earlier separate neutron and photon Monte Carlo transport codes. Given the confidence provided by the general benchmarking program and the analysts involved, these results should be acceptably accurate for the configurations described in this report. Finally, it can be noted that a special and rigorous benchmarking is most important only if the configuration is suspected to be very near critical; if the multiplication factor is substantially less than 1.0, the need for rigorous benchmarking is less compelling. 


\section{Appendix D The Meaning of Criticality and Margins of Safety}

This appendix reviews some basic ideas of reactor physics to enhance appreciation of the degree of safety implied by an effective multiplication factor, such as $k_{\text {eff }}=0.99$. In other contexts, this value would appear to be very close to a hazardous condition; but with the stringent requirements on the upper limit value of $k$, and the nature of neutron multiplication in a large volume of fuel (as in a power reactor), such a multiplication factor is quite safe.

The value of $k_{\text {eff }}$ can be expressed in terms of two factors: One, $k_{\infty}$, depends only on the material but not the amount because it assumes an infinite size; and the other, $\mathrm{L}$ (the neutron leakage factor), depends mainly on the size and shape of the material. Thus, $k_{\text {eff }}=k_{\infty} \times$ L. For a minute amount of fuel, the non-leakage probability is zero, meaning that all neutrons will escape, and $\mathrm{L}=0$. For an infinitely large size, the non-leakage probability is 1.0 , meaning that no neutrons will escape, and $L=1.0$. The dependence of these quantities on the size of the system can be seen in Table D1, which provides approximate data for a spherical mass of fuel plus water without soluble boron and at the optimum multiplication for which $k_{\infty}=1.407$.

Table D1. Effective multiplication factors and probabilities of non-leakage for various sizes of fuel material.

\begin{tabular}{lll}
\hline Radius $(\mathrm{cm})$ & $\mathrm{L}$ & $k_{\text {eff }}$ \\
\hline & & \\
10 & 0.492 & 0.62 \\
15 & 0.623 & 0.877 \\
19.85 & 0.711 & 1.000 (critical) \\
20 & 0.713 & 1.003 \\
25 & 0.776 & 1.092 \\
\hline
\end{tabular}

The physical characteristics that affect the multiplication factor and the critical mass can now be considered. The first is enrichment. Natural uranium, $0.71 \% 235 \mathrm{U}$, cannot be made critical under any condition with only a water moderator. Highly enriched uranium, which is about $93 \%{ }^{235} \mathrm{U}$, will go critical with as little as two pounds (about 840 grams) of fuel under the most favorable conditions. The fuel used in TMI-2, with three enrichments - 1.98, 2.64, and $2.96 \%$-is much nearer to natural uranium than to highly enriched uranium. However, the amount of fuel required for criticality increases dramatically with the addition of boron, as seen in Fig. D1. By the time 4500 ppm boron is reached, the critical mass is larger than the mass of fuel in TMI-2, and with another few hundred ppm, the fuel could not become critical no matter how much is assembled.

It is important to examine the trend in $k_{\text {eff }}$ and the mass of reactor fuel when the moderator contains a high boron concentration. The calculated figures for a fuel volume fraction of 0.63 at 4500 ppm are given in Table D2 and plotted in Fig. D2. 
Table D2. Mass of fuel and how it affects $k_{\text {eff }}$

\begin{tabular}{llll}
\hline Radius (cm) & $\mathrm{L}$ & $k_{\text {eff }}$ & $\begin{array}{l}\text { Mass of fuel } \\
\text { (metric tons) }\end{array}$ \\
\hline & & & \\
100 & 0.961 & 0.975 & 26.4 \\
125 & 0.974 & 0.988 & 51.5 \\
130 & 0.976 & 0.990 & 58.0 \\
150 & 0.982 & 0.996 & 86.1 \\
170 & 0.986 & 1.000 & 129.7 \\
\hline
\end{tabular}

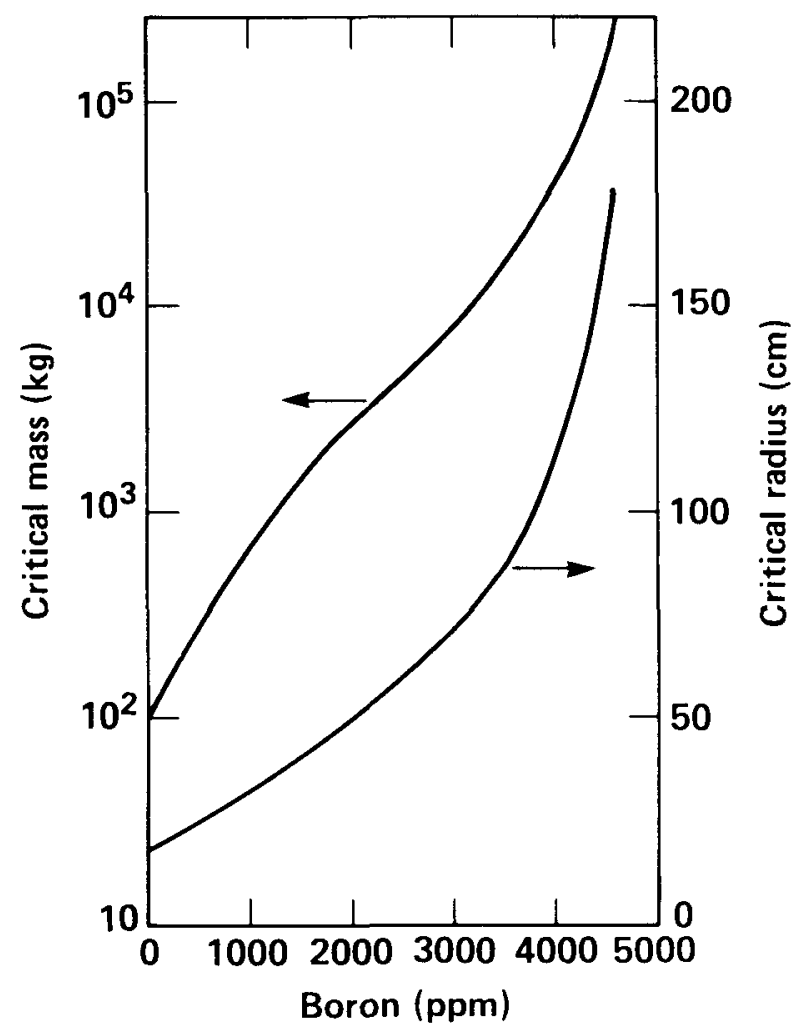

Figure D1. Approximate critical radii and masses of fuel at optimum moderation.

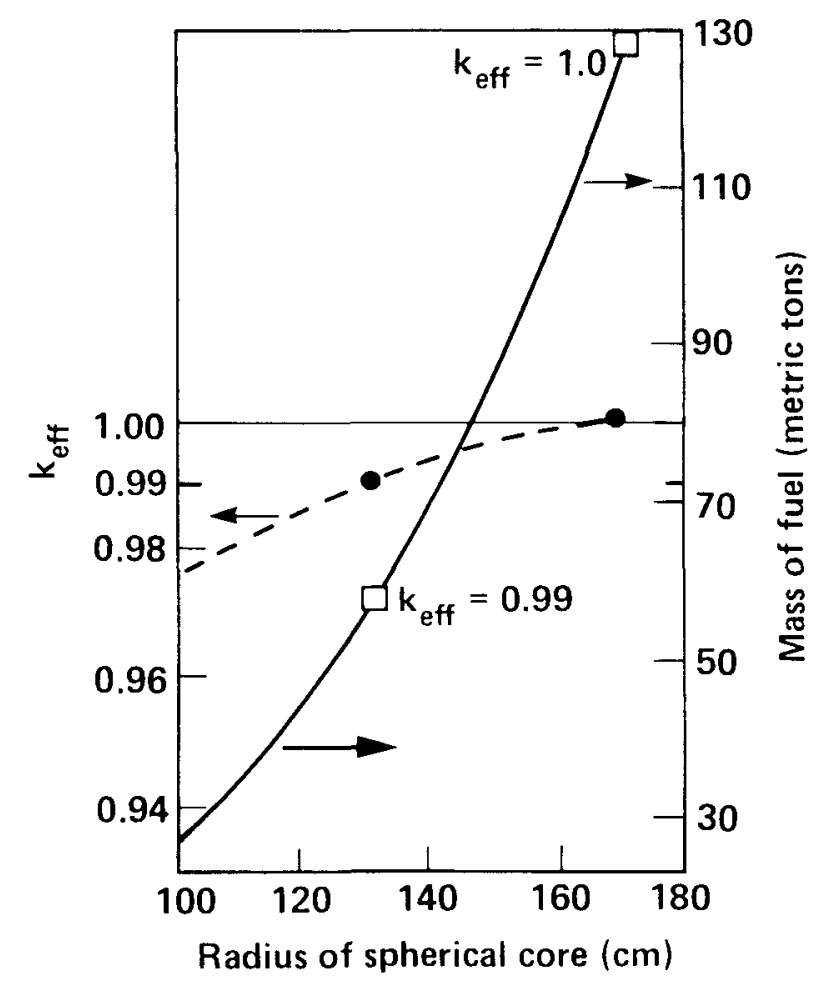

Figure D2. The relationship of $k_{\text {eff }}$ mass of fuel, and core size. Boron concentration is 4500 $\mathrm{ppm}$. Note that as $k_{\text {eff }}$ increases from 0.99 to 1.0 , the mass of fuel doubles.

The figure shows that going from $k_{\text {eff }}=0.99$ to $k_{\text {eff }}=1.00$ requires more than a doubling of the mass of fuel in the reactor. This means that, if a value of $k_{\text {eff }}=0.99$ can be assured without question, there is, indeed, a very large safety factor. 


\section{Appendix E \\ Borated Water Monitoring and Supply}

\section{Borated Water Monitoring}

The presence of boron in the primary coolant will ensure reactor shutdown during defueling operations. Maintaining the required boron concentration is important to assure that the defueling activities do not represent a potential hazard to plant personnel or to the public. Instead of neutron monitoring, it is necessary to monitor the boron concentration both to confirm that it remains within specifications, and also to provide data for detecting changes in plant conditions that might eventually result in low boron concentrations.

GPU Nuclear Corporation uses two approaches to assure that the required boron concentration is maintained during the defueling operations. The first approach determines possible sources of an unborated moderator or other fluids with low boron concentrations that could dilute the primary coolant; this approach takes action to eliminate the possibility of such an event. The second approach monitors the boron concentration directly.

GPU Nuclear Corp. has prepared a report, Hazards Analysis: Potential for Boron Dilution of Reactor Coolant System, ${ }^{19}$ which was submitted to the Nuclear Regulatory Commission as a reference for the Initial Plenum Jacking Safety Evaluation Report. The Hazards Analysis report evaluates potential dilution sources and paths for the reactor coolant system (RCS), and identifies actions that have been taken to reduce the likelihood of RCS dilution. These actions include:

- Double-valve isolation of possible dilution sources, coupled with daily checks of critical valve positions;

- Removal of spool pieces to physically disconnect dilution sources;

- Specific procedures corresponding to the unique conditions associated with various processing operations.

In addition to these actions, the Hazards Analysis report describes the methods to be used to monitor the boron concentration. These methods include both direct and indirect measurements. Direct measurement of the boron concentration involves chemical analyses of the weekly RCS samples or, in some cases, of the more frequent "grab" samples. The primary indirect method of boron concentration measurement is by monitoring the RCS level (hourly). In addition, several other indirect methods can be used for detecting a dilution event; in general, though, the value of these methods is limited under most circumstances. Table F1 (attached) of Ref. 19 provides a summary of recommended monitoring frequencies for the various methods of detecting a boron dilution. These are based upon a dilution volume of 5300 to 5800 gallons and a postulated rate of $15 \mathrm{gpm}$. It is our understanding that a boronometer capable of providing a continuous measure of boron concentration is being installed and will be operational in the near future.

The above Hazards Analysis is to be revised to support defueling. The new revision will identify appropriate isolation for the Defueling Water Cleanup System and will include a re-evaluation of required monitoring methods. For the purpose of this review, it is assumed that the revised analysis will be consistent with the existing analysis, and will not significantly modify any of the existing procedures. 
Table 6.1 Recommended monitoring frequencies for detection of boron dilution (prior to par)

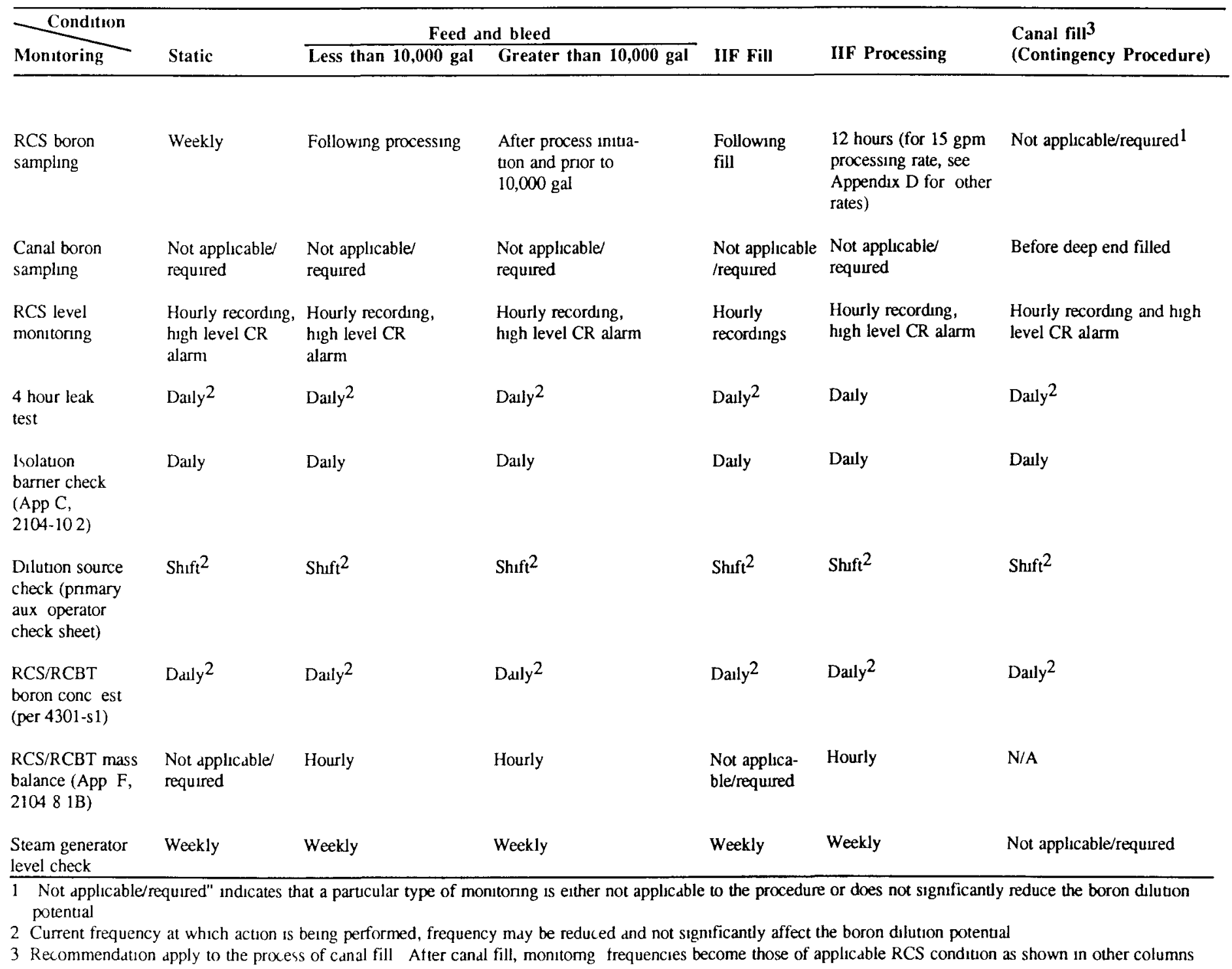




\section{Borated Water Supply}

In the event of an unisolatable leak from the reactor vessel, a means to restore borated water to the primary system has been provided." This emergency system is the reactor building Sump Recirculation System (SRS), described in Ref. 20. This system is designed to transfer water from the reactor building basement to the reactor vessel. The system will use two 200gpm submersible pumps, associated hoses and controls, and will keep the core covered for leak rates up to $400 \mathrm{gpm}$.

The system design is based on the following requirements and assumptions:

- The most probable reactor vessel leak is a corrosion-type failure of an in-core tube. The leak rate of this failure is assumed to be $17 \mathrm{gpm}$.

- Access to the reactor building is permitted.

- The mixture of water injected from the borated water storage tank (BWST) and the existing sump inventory results in a minimum boron concentration in the recirculated water of $4350 \mathrm{ppm}$.

- The BWST can be used to make up the leak until the sump is adequately borated and the SRS is installed.

- The SRS should be capable of delivering up to $400 \mathrm{gpm}$ and should have a backup to cover postulated single-active failures.

\footnotetext{
* The fuel would be far subcritical without water and would cool itself by natural convection of air. The water is needed for shielding to protect the workers in containment.
} 


\section{Appendix F Regulatory Shutdown Requirements}

The Nuclear Regulatory Commission's rules pertaining to the criticality safety of fissile material are included in the Code of Federal Regulations 10CFR50 for reactors, in 10CFR70 for fuel-fabrication facilities, and in 10CFR71 for fuel storage and shipment. In all cases, these rules require that inadvertent criticality be prevented; however, the rules do not prescribe specific shutdown margins.

NRC supplements the information in the Code of Federal Regulations by issuing Regulatory Guides. These Guides are intended to provide the licensee with detailed information on methods that are acceptable to the NRC for meeting the regulatory requirements in $10 \mathrm{CFR}$. The regulatory positions defined by these guides can be used, when applicable, to meet specific requirements. However, the licensee may use other methods to meet these requirements if the methods' suitability can be demonstrated. Several Regulatory Guides discuss matters related to criticality control, including numbers $3.4,3.41$, and 3.43 .

In the past, the NRC has addressed the subject of criticality control shutdown margins as consistent with the stated positions in the Guides. "Use of ANSI N16.5-197 is not a substitute for detailed nuclear criticality safety analyses for specific storage arrangements for fissile materials," and, "However, it will not be sufficient merely to refer to this guide in describing the validation of a method. The details...should be provided to demonstrate the adequacy of the safety margins...." In issuing licenses, NRC has approved shutdown margins that vary, depending on the specific conditions that apply to an application. Where for one application a shutdown margin of $5 \%$ was judged adequate, in another case a greater or lesser margin was required to cover analytical uncertainties.

In considering the use of Regulatory Guides for TMI-2 operations, it is important to recognize the unique characteristics of the plant. While it is possible that many of the existing Guides can be safely applied, each must be evaluated for its applicability to the special TMI-2 condition. With respect to the shutdown margin of the TMI-2 fuel during the defueling operations, the unique fuel configuration as well as other modeling and analytical uncertainties must be addressed. This safety evaluation must also consider specific accident scenarios and their effects on the shutdown margin. The existing Regulatory Guides and previous licensing actions offer little that is applicable to the in-core defueling activities. The storage and shipping activities are less specific to the TMI-2 situation.

GPU has reflected the above considerations in their approach to developing the shutdown requirements for the reactor coolant system during defueling operations of TMI- 2 . A specific safety evaluation report was prepared, which considered in detail the many elements that influence shutdown. The safety evaluation report presents conservative core configurations, fuel enrichments, moderator ratios, analytical techniques, and analytical uncertainties. The report shows that these conservative models demonstrate that the reactor remains subcritical even under extremely unlikely accident scenarios. In this case, shutdown means $1 \%$ subcritical. This margin is consistent with the model and analysis.

The regulatory adequacy of this approach is seen in the results of NRC's review of GPU's Criticality Report. ${ }^{6}$ The enclosure to NRC's letter of March 15, 1985, states:

"We conclude that the work described in the report represents an excellent job in exploring the problems of criticality for TMI-2 defueling, including the areas of geometry selection, parameter selection, calculation methodology, and uncer- 
tainty analysis. The resulting analysis leading to a selection of $4350 \mathrm{ppm}$ boron as a minimum level for operation is fully satisfactory and should ensure subcriticality through all reactor disassembly and defueling operations. In particular, it should assure at least one percent shutdown margin for an appropriate design-basis fuel model." 


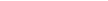

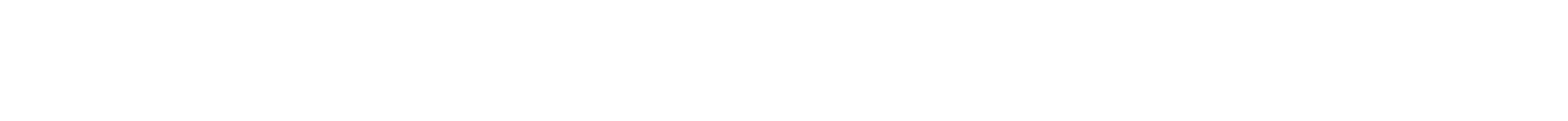




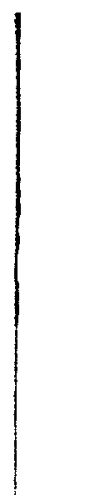

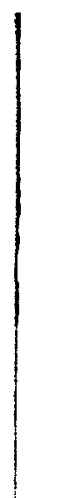

$+$

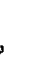

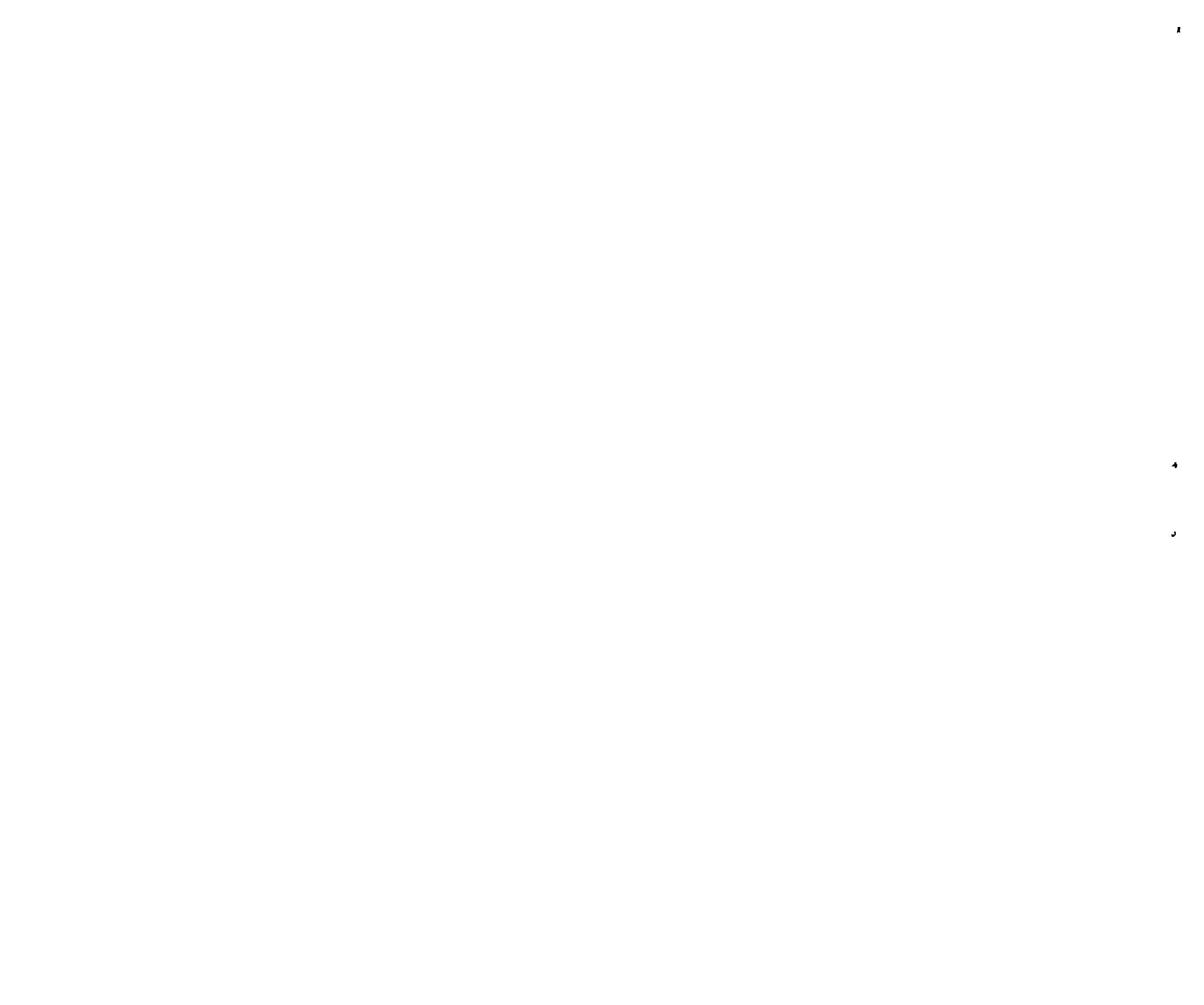




\section{NUCLEAR CRITICALITY TECHNOLOGY}

\section{DO NOT MICROFILM THIS PAGE}

